\title{
GENETIC CAUSES
}

1 Short abstract word count: 87

2 Long abstract word count: 217

3 Main text word count: 12,676

4 References word count: 5,520

5 Entire text word count: 18,912

6

\section{Building Causal Knowledge in Behavior Genetics}

${ }^{1}$ Department of Psychology, University of Texas at Austin, Austin, TX

$19{ }^{2}$ Population Research Center, University of Texas at Austin, Austin, TX

Correspondence to:

23 James W. Madole, M.A., Department of Psychology, The University of Texas at Austin, 108 E. Dean Keeton Street, Stop A8000, Austin, TX 78712, USA. E-mail: jmadole@utexas.edu

K. Paige Harden, Ph.D., Department of Psychology, The University of Texas at Austin, 108 E. Dean Keeton Street, 
35 We advance a framework for identifying, interpreting, and applying causal effects of genes on

36 human behavior. First, we describe counterfactual reasoning as the scaffold for building causal

37 knowledge in social science. Next, we describe how genetic inheritance from parents to children

38 is a natural experiment, and explain how genetic causes identified using family designs have the

39 same interpretational boundaries as average treatment effects from randomized controlled trials.

40 Knowledge of these effects can be used to improve causal understanding of human behavior and

41 guide prevention and intervention efforts. 


\section{Long Abstract}

43 Behavior genetics is a controversial science. For decades, scholars have sought to understand the

44 role of heredity in human behavior and life-course outcomes. Recently, technological advances

45 and the rapid expansion of genomic databases have facilitated the discovery of genes associated

46 with human phenotypes like educational attainment and substance use disorders. To maximize

47 the potential of this flourishing science, and to minimize potential harms, careful analysis of

48 what it would mean for genes to be causes of human behavior is needed. In this paper, we

49 advance a framework for identifying instances of genetic causes, interpreting those causal

50 relationships, and applying them to advance causal knowledge more generally in the social

51 sciences. Central to thinking about genes as causes is counterfactual reasoning, the cornerstone

52 of causal thinking in statistics, medicine, and philosophy. We argue that within-family genetic

53 effects represent the product of a counterfactual comparison in the same way as average

54 treatment effects from randomized controlled trials (RCTs). Both average treatment effects from

55 RCTs and within-family genetic effects are shallow causes: they operate within intricate causal

56 systems (non-unitary), produce heterogeneous effects across individuals (non-uniform), and are

57 not mechanistically informative (non-explanatory). Despite these limitations, shallow causal

58 knowledge can be used to improve understanding of the etiology of human behavior and to

59 explore sources of heterogeneity and fade-out in treatment effects.

60

61

62 Keywords: behavior genetics, causal inference, counterfactual reasoning, experimental designs, 63 individual differences, philosophy of science 64 


\section{Introduction}

66 Violent crime is endemic to human society. The second-century poet Juvenal described Ancient

67 Rome as having "no shortage of thieves" and "many opportunities to die" (Juvenal, 1769). Court

68 records from thirteenth-century England show that "murderous brawls and violent death ... were

69 everyday occurrences.” (Gurr, 1981, pp. 305). Now, statistics suggest that 2020 was America’s

70 "most violent year in decades", with more than 19,000 people killed in firearm-related incidents

71 (Time Magazine, 2020). Understanding why people act in violent and criminal ways remains a

72 societal imperative.

74 In a 2013 address, then President Barack Obama offered one possible avenue for reducing crime:

75 improving early childhood education. "Every dollar we invest in high-quality early childhood

76 education,” said Obama, “can save more than \$7 later on by ... reducing crime.” (Obama, 2013).

77 At its core, this statement communicates the causal hypothesis that high-quality childhood

78 education will reduce crime. This hypothesis about a cause-effect relationship takes the form of a

79 counterfactual statement about what could be. If the availability of high-quality childhood

80 education were different, Obama predicts, then crime rates would also be different.

82 As social scientists, one of our primary aims is to produce research that verifies or challenges

83 these sorts of causal claims. We examine evidence as to whether a causal relationship exists

84 between two variables, offer theories for interpreting causal associations, and evaluate whether

85 causal knowledge can be effectively applied to improve public health and well-being. As we will

86 explain in this paper, this process of evaluating causes in social science relies heavily on

87 counterfactual thinking, and it often begins by manipulating a variable in a randomly selected 
88 group of people. As we will also explain in this paper, this process of evaluating causes in social

89 science is not limited to environmental exposures like early childhood education. The same

90 process of evaluating causes applies even when the causes in questions are variables less

91 commonly considered by social scientists: genes.

92

\section{1.1 Environmental causes in the social sciences: An empirical example}

94 In the early 1960s, disadvantaged children living in Ypsilanti, Michigan were randomly assigned

95 to an intensive two-year preschool education program (High/Scope Perry Preschool Program

96 (HPPP)) that involved over two hours of daily active learning and weekly home visits from

97 teachers (Schweinhart, Barnes, \& Weikart, 1993). Children of the same age and socioeconomic

98 background who were not assigned to this program received no preschool education. All

99 participants were assessed throughout the first 40 years of life to determine the effects of the

100 education program on outcomes such as educational attainment, economic earnings, and criminal

101 behavior (Belfield, Nores, Barnett, \& Schweinhart, 2006).

102

103 This methodological design, known as a randomized controlled trial (RCT), serves as the gold-

104 standard for validating the sorts of causal claims advanced by President Obama. By randomly

105 assigning participants to different levels of a manipulated variable (in this case, preschool

106 education), researchers were able to approximate the counterfactual scenario of what would have

107 happened if conditions had been different. We can observe both the rate of criminal behavior in

108 those who were given the treatment of better education and the rate of criminal behavior among

109 children whose lives proceeded as usual (the control group). Relative to the control group, those

110 children who participated in the high-quality preschool education program received over $50 \%$ 
111 fewer total arrests and over $80 \%$ fewer charges for violent crimes by age 40 (estimates based on

112 data presented in Heckman, Moon, Pinto, Savelyev, \& Yavitz, 2010). Because of the

113 experimental design of this study, we can conclude that President Obama was correct: improving

114 early childhood education caused a reduction in adult criminal outcomes.

116 This conclusion is more meaningful than merely observing a correlation between attending

117 preschool and (not) committing crimes. As social scientists, we privilege inferences about causal

118 relationships over such correlational ones and believe that they reveal something unique about

119 the world. As this paper will show, the conclusion that good preschool education causes an

120 average reduction in adult criminal behavior is distinctive, but how we interpret and apply this

121 knowledge depends on the type of causation implied by experimental designs.

123 To further illustrate both the power and the limitations of this causal knowledge, consider that of 124 the six individuals from the HPPP study who went on to incur the greatest number of lifetime 125 criminal charges, three of them had actually participated in the preschool education program

126 (Heckman, Moon, Pinto, Savelyev, \& Yavitz, 2010). So, despite being exposed to a program that

127 "causes" a reduction in criminal behavior, these individuals nevertheless received a total of 110

128 criminal charges between them. At the same time, the specific mechanisms underlying the effect 129 of preschool education on crime are opaque. Indeed, researchers were surprised to observe the 130 effects of preschool on adult outcomes, as the benefits of the intervention had appeared to fade 131 out entirely in middle childhood (Heckman, 2006). Whatever intermediary process linked an 132 educational experience at age 4 with a behavior committed (or not committed) by age 40 is not 133 known (Schneider \& Bradford, 2020). Clearly then, the causation implied by the experimental 
134 paradigm does not suggest that preschool education is the sole determinant of a person's lifetime

135 criminal behavior, nor that the criminal behavior of any single individual can be attributed to the

136 preschool education they received, nor does it explain anything about the mechanisms generating

137 individual differences in the relationship between preschool education and criminal behavior.

139 Nevertheless, knowing that preschool education makes an average difference in adult criminal

140 behavior is useful. Most directly, this knowledge has led to calls for policy changes in the US to

141 develop and disseminate childhood education programs. That is, the most straightforward

142 application of the observation that changing $\mathbf{X}$ produced an average difference in $\mathbf{Y}$ is to develop

143 intervention and prevention programs that target $\mathbf{X}$ on a large scale. In this paper, we refer to this

144 application as first-generation causal knowledge. Knowing that $\mathbf{X}$ caused $\mathbf{Y}$ in one group of

145 people implies that one could change $\mathbf{Y}$ in future groups of people by changing $\mathbf{X}$.

147 As many interventionists and policymakers can attest, however, first-generation causal

148 knowledge can be quite limited (Bryan, Tipton, \& Yeager, 2021). Treatment effects often fail to

149 sustain over time, to generalize to other samples, or to behave in predicted ways (Bailey et al.,

150 2020). Further, even when these effects show maintenance and durability across time and place,

151 they often operate through unobserved mechanisms, obfuscating deep understanding of the

152 effect. We may know that improved preschool education causes decreases in crime, but we have

153 limited understanding of for whom this effect will hold, why it holds, for how long it will last, or

154 how portable this effect will be across environmental contexts. 
156 This type of information is what we refer to in this paper as second-generation causal

157 knowledge. By revealing sources of heterogeneity and mechanisms supporting the durability of

158 causal effects, we can better understand when, where, why, for whom, and for how long $\mathbf{X}$

159 makes some difference in $\mathbf{Y}$ - and this knowledge gives us more avenues for effecting change.

160 Knowing that preschool education makes an average difference in adult criminal behavior is

161 useful not only because we identify preschool education as a potential intervention target, but

162 also because we can begin to examine the causal pathway from early education to adult crime to

163 identify other intervention targets whose manipulation might yield larger, more enduring, or

164 more generalizable changes in criminal behavior.

165

166 1.2 Evaluating genetic causes in the social sciences: An impossible or worthless task?

167 Let us consider another causal hypothesis: certain genetic variants cause violent and criminal

168 behavior. To support this claim, we might point to behavior genetics research on the heritability

169 of antisocial behavior (see Lahey, Waldman, \& McBurnett, 1999 \& Moffitt, 2006 for review)

170 and on specific measured DNA variants that can predict antisocial behavior and involvement

171 with the criminal justice system (Tielbeek et al., 2017; Karlsson Linnér et al., 2021). Likely, the

172 suggestion that genetic variants cause criminal behavior triggers a stronger intuitive response

173 from many of our readers than the suggestion that being deprived of an education in early

174 childhood causes criminal behavior. Claims about genetic causes are more controversial, both to

175 our fellow scientists and to the general public, than claims about environmental causes. As the

176 biologist Richard Dawkins noted almost four decades ago, genes have acquired a "sinister,

177 juggernaut-like reputation" (Dawkins, 1982/2016, pp. 12). 
178 Genetics' sinister reputation has historical roots: in the $20^{\text {th }}$ century, results from the nascent field

179 of behavioral genetics were used to justify state-sponsored violence against the

180 socioeconomically disadvantaged and people of color, including forcible sterilizations. This

181 history is - and will likely continue to be - a stumbling stone for those asked to consider the idea

182 that genetic differences between people could cause the behavioral outcomes that are the

183 province of social science.

184

185 Despite these fears that genetics will be misused to justify racist and classist oppression, the 186 search for genetic markers of human behavior is accelerating. The past decade has witnessed a 187 rapid expansion in the collection and analysis of genomic data. As of June 2021, more than 38

188 million individuals had contributed DNA to ancestry-testing companies (Janzen, 2021) and over 189 5,000 genome-wide association studies (GWASs) had been published (Buniello et al., 2019).

190 This includes GWASs of social and behavioral phenotypes, such as educational attainment (Lee 191 et al., 2018), household income (Hill et al., 2019), and criminal activity (Tielbeek et al., 2017).

192 As ancestry-testing companies and national biobanks continue accrue DNA samples from

193 millions of individuals, and as genetic variants continue to demonstrate associations with more

194 and more biologically-distal life outcomes, scientists have an outstanding responsibility to

195 address the implications of genomic research.

196

197 The obvious shadow cast by the history of eugenics can make it difficult to see another

198 stumbling block to considering claims about genetic causation: a widespread confusion about

199 how genetic research in humans could ever establish causation, or what such causal knowledge

200 would ever be good for, in the absence of the ability to tinker directly with people's genes. The 
201 goal of this paper is to resolve this stumbling block by describing how certain genetic research

202 designs do, in fact, map onto what social scientists already know about establishing causal

203 relationships and applying causal knowledge. By describing a clear perspective on what it does -

204 and does not - mean for genes to be causes, and how that causal knowledge can be ethically

205 applied, we also challenge the genetic determinism and essentialism that have historically

206 characterized the pernicious misapplications of genetics by political extremists.

208 Let us consider the problem in more detail. Why might the prospect of establishing genetic 209 causes of human behavior seem difficult to the point of impossibility? Recall that the first step

210 for testing a cause in a randomized controlled trial is to manipulate the variable-of-interest in a

211 randomly selected group of people. In many corners of biology, manipulating the genome is not

212 only viable, but widely practiced. Researchers studying rodents, insects, and sea and plant life

213 commonly use gene-modification strategies (e.g., knockout, selective breeding) as a means of

214 gaining experimental control (Nagy, Perrimon, Sandmeyer, \& Plasterk, 2003). These techniques

215 allow for a direct assessment of the (counterfactual) casual hypothesis that if the organism's

216 genome had been different, the outcome would have been different too. But when it comes to

217 testing causal hypotheses about the human genome, the very idea of experimental manipulation

218 is provocative at best and contemptible at worst. Gene-editing technologies like CRISPR have

219 demonstrated that direct alteration of the human genome is possible, but the use of these

220 technologies on any meaningful scale is both scientifically nascent and ethically ambiguous

221 (Gaskell et al., 2017). Regardless of one's moral appraisal of gene modification in humans, the

222 fact remains that at present, manipulating the genomes of a randomly selected group of people is

223 not a practicable option for testing hypotheses about the genetic causes of human behavior. 
225 Moreover, even if we concede that, at a conceptual level, genes could cause average differences

226 in human behavior, then at a practical level, it is not readily apparent what we would $d o$ with this

227 knowledge. As Evelyn Fox Keller wrote, "[t]he major practical interest driving the search for the

228 relative importance of different causal factors in producing a given phenomenon is to be found in

229 the wish to effect change in that phenomenon.” (Keller, 2010, pp. 8). But, for the same reasons

230 that we discussed above, we cannot (and should not) readily apply knowledge of genetic causes

231 to change the genomes of large swathes of the population in the hopes of changing their

232 outcomes. Indeed, many of us cannot even engage in that thought experiment without feeling

233 anxiety or revulsion at the prospect. As a consequence, it might be easy to conclude that

234 establishing genetic causes of human behavior, even if it could be accomplished, is not a

235 worthwhile endeavor. The first-generation fruit of that causal knowledge, the idea that we could

236 change behavior by changing people's genes, seems poisonous.

\section{$238 \quad 1.3$ Goals of the current paper}

239 This skepticism about the feasibility and value of establishing genetic causes, however intuitive

240 and well-meaning it might be, is mistaken. As we discuss in this paper, genetic causes are like

241 nearly all environmental causes investigated in the social science: they are non-uniform, non-

242 unitary, and non-explanatory. Indeed, most genetic causes, when appropriately identified, can be

243 interpreted along the same lines as average treatment effects estimated from RCTs or other

244 natural experiments. Genetic causes, like environmental ones, are not deterministic, explanatory,

245 or homogeneous across place and time, but they do make an average difference in social and

246 behavioral outcomes. 
248 We also consider not just the feasibility of causal inference about genes but also the utility of that 249 endeavor. We propose that knowledge about genetic effects on important life outcomes can help 250 us change people's lives for the better, and that these changes may be brought about via social 251 science (i.e., environmental) interventions, not by manipulating genomes. Specifically, we call 252 attention to second-generation causal knowledge. Examining the causal pathways from genes to 253 life-course outcomes allows us to improve etiological understanding, uncover sources of 254 heterogeneity in those outcomes, and identify novel targets for intervention. 


\section{2. What is a cause and how do we identify them? A brief review of causal inference in the}

\section{6 social sciences}

257 For decades, the scholarly community has been polarized by how to interpret findings from

258 genomics research (Figure 1). For some, the complexity of processes that span genes and

259 behavior and the dynamic interplay between genes and environment preclude researchers from

260 gleaning any sort of meaningful causal knowledge from behavioral genetic research designs

261 (Lewontin, 1974/2006; Block, 1995; Turkheimer, 2011). For others, heritability estimates and

262 correlations with measured genotypes are sufficient evidence that genes determine life outcomes

263 (Jensen, 1969; Herrnstein \& Murray, 1994; Murray, 2020). And for still others, genes are neither

264 non-causal nor supra-causal, but are rather causes of human behavior in a more circumscribed,

265 probabilistic sense (Dawkins, 1982; Bourrat, 2018). How to decide among these competing

266 interpretations?

268 We think that the seemingly intractable conversation about how to interpret the results of

269 behavioral genetic research can be advanced by first considering a more general, and less

270 controversial question: how do social scientists typically think about (non-genetic) causes and

271 how do they go about finding them? 
"Complex human behavior emerges out of a hyper-

complex developmental network into which individual

genes and individual environmental events are inputs.

The systematic causal effects of any of those

inputs are lost in the developmental complexity of

the network." (Turkheimer, 2011)

"So what counts as genetic variance ... is a matter

of value judgments and of what effects we know

about. Surely this makes heritability a lousy

scientific concept." (Block, 1995)

"The simple analysis of [genetic and environmental]

variance is useless for these purposes and indeed it

has no use at all." (Lewontin, 1974)

\section{3}

274 Figure 1. Pendulum of historical perspectives on what causal knowledge can be obtained from human behavioral genetics.

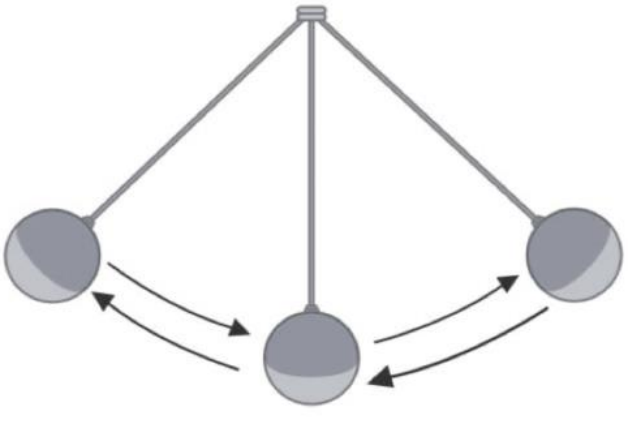

"DNA is the major systematic force, the blueprint, that makes us who we are." (Plomin, 2018)

"[A]s America equalizes the circumstances of people's lives, the remaining differences in intelligence are increasingly determined by differences in genes."

(Hermstein \& Murray, 1994)

"The important fact is that currently used IQ tests do indeed reflect innate, genetically determined aspects of intellectual ability." (Jensen, 1967)
"These different cases indicate that if the causal relationships between SNPs and phenotype, and consequently their aggregation and normalization into emulate - the minimal criterion of causation, the type 'genetic' causal relationships they capture have restricted ranges of influence." (Bourrat, 2020)

"When a geneticist speaks of a gene 'for' red eyes in Drosophila, he is not speaking of the cistron which Dets as template for the synthers of the red pigment molecul. He is implicitly saying: there is varition in eye colour in the population; other things being

equal, a fly with this gene is more likely to have red eyes than a fly without the gene." (Dawkins, 1982) SNP heritability estimates, satisfy - or more accurately 


\section{1 "No causes in, no causes out"}

276 Determining that a relationship is causal requires more than plugging data into statistical models.

277 It requires causal concepts (Pearl, 2009). Conceptual definitions of causation have historically

278 been expressed in terms of active behavior - a cause "produces (Locke, 1690/1997), "forces"

279 (Lakoff, 1993), "changes" (Charlton, 1983). Empirical tests of causation, therefore, involve

280 detecting such activity, and not all statistical associations are up to the task. The familiar adage

281 "correlation does not equal causation" is founded on precisely this principle, that a statistical

282 association between two variables does not inherently demonstrate that one of those variables

283 produced or changed the other. Identifying statistical causes means grounding statistical models

284 in causal concepts and assumptions. In other words, "no causes in, no causes out" (Cartwright, 285 1995, pp. 154).

286

287 The predominant causal concept in scientific thinking is the counterfactual (Pearl, 2018).

288 Counterfactuals refer broadly to any hypothetical situation that describes what would have 289 happened if conditions had been different. In 1973, David Lewis asserted that the counterfactual 290 was the cornerstone of causal reasoning, arguing that $\mathbf{X}$ is a cause of $\mathbf{Y}$ if (a) when $\mathbf{X}$ occurs, $\mathbf{Y}$

291 occurs and (b) holding everything else equal, had $\mathbf{X}$ not occurred, $\mathbf{Y}$ also would not have

292 occurred (Lewis 1973a). Boiling water causes a tea kettle to whistle because (a) when water boils 293 in a kettle, it whistles and (b) under identical conditions, had water not been boiling in the kettle, 294 it would not have whistled. Causation, in this view, is a matter of counterfactual dependence 295 (Lewis, 1973b). 
297 Counterfactual logic marked a departure from thinking about causation in terms of the regular 298 occurrence of two variables. Regularity accounts of causation, which had dominated much of the 299 history of causal reasoning, required that for $\mathbf{X}$ to cause $\mathbf{Y}, \mathbf{Y}$ must invariably follow $\mathbf{X}$ (Hume, 300 1748/1999; Mill, 1843/2002; Mackie, 1965). Relying on the constant conjunction of two

301 variables for causation, however, is problematic. Among the problems of regularity accounts is 302 that they evoke the thorny concepts of necessity (whether $\mathbf{X}$ must be present for $\mathbf{Y}$ to occur) and 303 sufficiency (whether $\mathbf{X}$ alone can bring about Y) (Hulswit, 2002). Counterfactual definitions 304 relieve the need for $\mathbf{Y}$ to be necessarily or sufficiently dependent on $\mathbf{X}$. Boiling water causes a 305 tea kettle to whistle, but it is neither necessary (we can create steam in a kettle without boiling 306 water), nor sufficient (if the water is boiling but the spout is open, the kettle will not whistle).

308 Despite these strengths, the counterfactual dependence account offered by Lewis (1973b) has 309 limitations ${ }^{1}$. First, it fares no better than regularity accounts at ruling out third causal variables.

310 Borrowing an example from Woodward (2005), the reading of a barometer and the occurrence of 311 a storm are counterfactually dependent on one another, such that if the barometer reading 312 dropped, a storm would occur and if the barometer reading had not dropped, the storm would not 313 have occurred. Nevertheless, they are not causally related. Both are caused by a third variable, 314 namely, atmospheric pressure (Woodward, 2005). Second, counterfactual dependence does not 315 explain the direction of the causal effect (Brady, 2011). Observing the co-occurring presence and 316 absence of two variables does not reveal which of those variables is causally responsible for the 317 other. Third, and perhaps most critically, the Lewis counterfactual is subject to what Paul 318 Holland (1986) referred to as the fundamental problem of causal inference: it is impossible to 
319 simultaneously observe $\mathbf{X}$ and not-X. The same kettle of water cannot be boiling and not boiling

320 at the same time.

322 Manipulationist accounts of causation address some of these limitations. Like Lewis'

323 counterfactual, manipulationist thinking relies on hypothetically comparing what would happen

324 to $\mathbf{Y}$ under different conditions of $\mathbf{X}$. Where it deviates is in reserving causal efficacy for those

325 counterfactual situations "that describe how the value of one variable would change under

326 interventions that change the value of another." (Woodward, 2005, pp. 15). The critical shift here

327 is from an emphasis on counterfactual dependence to counterfactual control (Ross, 2015).

328 Manually changing the reading on a barometer will not cause a storm to occur because the

329 barometer lacks causal control over the weather (Woodward, 2005).

331 This subtle shift from dependence to control has important advantages. First, it ensures that the

332 detected relationship is not an artifact of a common cause. If intervening on $\mathbf{X}$ changes $\mathbf{Y}$ (or the

333 probability of $\mathbf{Y}$ ), then holding everything else constant, this rules out the possibility that $\mathbf{X}$ and

$334 \mathbf{Y}$ just happen to change together because of $\mathbf{Z}$ (Ross, 2018). Second, it allows us to determine

335 the direction of the effect. Designating one variable to be manipulated and one to respond

336 establishes temporal precedence and helps to segregate cause from effect (Hill, 1965/2015). That

337 just leaves the fundamental problem of causal inference - how can we simultaneously observe

338 the changed and unchanged versions of $\mathbf{X}$ ? For that, we need to create parallel worlds. 


\subsection{Parallel worlds and potential outcomes}

341 In the United States, more than 256,000 children and adolescents have witnessed or died from

342 school shootings in the past two decades (Cox, Rich, Chiu, Muyskens, \& Ulmanu, 2018). The

343 median age of assailants is sixteen years old (Cox et al., 2018). While we know that changing

344 preschool education is an effective means of reducing violent crime, if we have already missed

345 the opportunity to improve an individual's preschool experience, we must develop other methods

346 for reducing violent and aggressive behavior during critical developmental windows. Suppose

347 you think that, for gun violence to end, adolescents need to be more compassionate toward one

348 another. Equipped with an understanding of the relevant causal concepts, you know that to

349 demonstrate that compassion causes a reduction in violent behavior, you need to manipulate

350 compassion and see how violent behavior responds. For example, you might design a curriculum

351 for first-year high school students that increases awareness of positive emotions and strengthens

352 empathic communication skills. To test whether this intervention works, you need to create

353 parallel worlds, running with the exact same conditions at the exact same time, save for one

354 single difference: the presence of the compassion intervention. Each world then hosts a range of

355 potential outcomes, in this case, the prevalence of violent behavior. The difference in the

356 observed outcomes across these worlds represents the causal effect of the compassion

357 intervention on violent behavior.

359 In social science, the simulation of parallel worlds and potential outcomes most often takes the

360 form of a randomized controlled trial (RCT; Fisher, 1925). We create parallel worlds by

361 assigning different, but similar, people to different conditions of an intervention (i.e., treatment

362 groups). We consider the response of each treatment group as a representation of potential 
363 outcomes, of what would have happened given the opposite condition. We summarize the causal

364 effect by taking the difference of the average effect for each treatment group (average treatment

365 effect (ATE; Rubin, 2005)). RCTs entitle causal inference because they translate those theoretical

366 causal concepts - manipulation, counterfactual control, parallel worlds, potential outcomes -

367 into empirical action. They provide an algebra of the counterfactual (Pearl, 2010).

369 How well an RCT approximates these causal concepts, however, depends on how well it meets

370 four critical assumptions: independence, sample homogeneity, potential exposability, and SUTVA

371 (stable unit treatment value assumption). Together, these assumptions build confidence that a

372 study truly tests whether $\mathbf{X}$ has causal control over $\mathbf{Y}$. Fortunately, most of these are satisfied (at

373 least in expectation) by a single methodological tool: randomization. By randomizing

374 participants to treatment groups, we neutralize any dependency between treatment assignment

375 and outcome (independence; Holland, 1988), and we balance the treatment groups on all

376 variables other than $\mathbf{X}$ (sample homogeneity; Rubin, 1974). Randomization thus forms the basis

377 of our parallel worlds, ensuring that the mechanism splitting our sample into respective worlds

378 operates in a way that maximizes the uniformity of these worlds. Any causal effect is therefore

379 attributable to the control of $\mathbf{X}$ over $\mathbf{Y}$, and not to any artifactual differences between these

380 worlds.

381

382 Randomization also helps confirm that all participants can be potentially assigned to any of the 383 treatment conditions (potential exposability; Jo \& Muthén, 2001). This marks the first step

384 toward preserving the comparison of potential outcomes. If certain participants are unable to

385 receive one of the treatment conditions - that is, if $\mathbf{X}$ cannot be manipulated for them - then the 
counterfactual collapses. Holland's (1986) proclamation "No causation without manipulation" is

387 emphasized for exactly this reason (pp. 959). If $\mathbf{X}$ cannot be changed, then the potential outcome

388 of what would have happened had $\mathbf{X}$ been different does not exist, and no causal comparison can

389 be drawn. Importantly, this proclamation can be extended to cover scenarios in which $\mathbf{X}$ is only

390 hypothetically manipulatable, but where pragmatic or ethical considerations limit its ability to be

391 manipulated in practice (Holland, 1986; Woodward, 2005).

392

393 If randomization sets the counterfactual conditions of a study into motion, SUTVA guarantees

394 that they persist as the study unfolds. SUTVA protects the uniformity of parallel worlds and the

395 openness of potential outcomes by stipulating that (a) participants in each treatment group

396 receive identical forms of the treatment and (b) the outcome for each participant is not influenced

397 by the treatment assignment of another participant (Rubin, 1980). Uniting these tenets is the

398 overarching principle that, once parallel worlds have been set to run, no new worlds are created.

399 Consider, for example, if instead of receiving the same compassion curriculum, some students

400 received education focused on building communication skills, while others learned mindful

401 breathing or expressive writing. We could no longer meaningfully compare the potential

402 outcomes of $\mathbf{X}$ and not-X because $\mathbf{X}$ would represent several divergent conditions. Likewise, if

403 participants from the treatment group share their discoveries with members from the control

404 group, then our parallel worlds have intersected and opened new counterfactual doors. For the

405 difference between potential outcomes to have causal validity, the parallel worlds initiated by

406 randomization must be preserved throughout the study. In theory, "SUTVA is automatically

407 satisfied under the Fisher (1935) null hypothesis of absolutely no treatment effects of any kind"

408 (Rubin, 1986, pp. 961), though in practice, meeting SUTVA involves careful methodological 
409 design and statistically testing the magnitude of potential interference (Hudgens \& Halloran,

410 2008; Sobel, 2006).

\section{$412 \quad 2.3$ Conceptualizing causes}

413 We began with causal concepts. Next, we translated those concepts into empirical parameters

414 and assumptions in the form of an RCT. The final step is to export a causal conclusion. Yet

415 drawing an appropriate causal conclusion is not always straightforward. For one, there are many

416 different kinds of causal relationships - some are general rules, others are specific instances;

417 some are direct, whereas others are bridged by a cascade of intermediary forces (Hausman, 2005;

418 Rottman \& Hastie, 2014). Moreover, a statistical parameter, by itself, provides little insight into

419 the type of observed causal relationship. An ATE reveals only that there is a mean difference

420 between groups. When it comes to interpreting instances of counterfactual control, however,

421 philosophers have established a set of dimensions along which causal relationships can be

422 conceptualized (see Woodward, 2010 on stability, specificity, and levels of explanation). Because

423 RCTs simulate counterfactual conditions, these dimensions can be readily exported and applied

424 to interpreting ATEs (see Deaton \& Cartwright, 2018). In most of the social sciences, ATEs are

425 perhaps best understood by describing what they are not: they are not uniform, not unitary, and

426 not explanatory.

428 Uniform causes produce effects in the same way every time. For example, atmospheric pressure

429 invariably causes a barometer to drop. At least in theory, we often presume that treatment effects

430 will behave uniformly (unit homogeneity; Holland, 1986). Despite this expectation, we often

431 observe substantial heterogeneity in treatment effects (Angrist, 2004; Kent, Rothwell, Ioannidis, 
432 Altman, \& Hayward, 2010). This is an important indication of the type of observed causal

433 relationship - it tells us that the observed relationship is probabilistic rather than deterministic.

434 Heterogeneity indicates that the cause does not affect the outcome in the exact same way across

435 person, place, or time. And indeed, this is what we find in RCTs: "there is no warrant for the

436 convenient assumption that the ATE estimated in a specific RCT is an invariant parameter, nor

437 that the kinds of interventions and outcomes we measure in typical RCTs participate in general

438 causal relations" (Deaton \& Cartwright, 2018, pp. 13-14). This limits the ideographic and

439 external validity of ATEs. They do not tell us about singular causes (i.e., that $\mathbf{X}$ is the cause of $\mathbf{Y}$

440 in a specific instance for a specific person), nor do they tell us about general claims (i.e., that $\mathbf{X}$

441 will cause $\mathbf{Y}$ in all places at all times) (see Cartwright, 1988 for a discussion of singular versus

442 generic causes).

443

444 Unitary causes produce effects entirely on their own. Atmospheric pressure, for example, is

445 singularly capable of dropping the reading on a barometer. Heterogeneity in treatment effect

446 provides another important indication here. It tells us that the causal relationship is dependent on

447 the presence of other factors (i.e., moderators). Adolescents with a large emotional vocabulary

448 may show a greater reduction in aggressive behavior after a compassion intervention than those

449 with more limited vocabularies. In this case, compassion is not causally exclusive, but rather, its

450 effect on violent and aggressive behavior is embedded within a system of other causes whose

451 collective function brings about the outcome. This renders ATEs local parameters that reflect

452 causes that are inextricably tied to the demographic composition and environmental context of

453 the measured sample.

454 
455 Explanatory causes provide a description of how the cause brought about the effect. For

456 example, atmospheric pressure causes a barometer to drop by changing the balance of the weight

457 of mercury and the air pressure inside of the barometer. In contrast, ATEs tell us only that

458 changing one variable will change the other, without explaining how this change comes about

459 (Woodward, 2002). This explanatory, or causally distal, gap divorces causes from mechanisms.

460 Mechanisms can be conceptualized as complex causal systems whose interrelated parts

461 collectively produce an effect (Glennan, 1996). Identifying mechanisms requires (a)

462 decomposing the effect into the component processes extending from cause to effect and (b)

463 articulating how those processes function together to generate an outcome (Craver \& Darden,

464 2013). These are different concepts than those at work in RCTs, so their empirical validation

465 requires a different set of scientific practices.

466

\section{$467 \quad 2.4$ First- and second-generation causal knowledge}

468 In 1949, John Cade reported a series of case studies finding that lithium salts helped to pacify

469 "psychotic excitement" (Cade, 1949). In his initial report, Cade called for "controlled

470 observation of a sufficient number of treated and untreated patients" to test more conclusively

471 whether differences in lithium administration caused differences in manic symptoms (Cade,

472 1949, pp. 518). Seventy years, and dozens of controlled trials later, lithium has been heralded as

473 a "psychiatric success story" (Draaisma, 2019, pp. 584). The well-established knowledge that

474 lithium makes an average difference in manic symptoms has been packaged into the first line of

475 treatment for bipolar disorder in clinical practice (Volkmann, Bschor, \& Köhler, 2020; Draaisma,

476 2019). "I don’t believe in God," wrote Jaime Lowe, "but I believe in Lithium.” (Lowe, 2015,

477 para. 35). 
479 The "controlled observations" upon which the efficacy of lithium was established constitute what

480 we refer to as first-generation causal knowledge. This is the knowledge that a variable makes a 481 non-uniform, non-unitary, and non-explanatory (i.e., average) difference in an outcome. As we

482 have demonstrated so far, this is the type of information that is gained from standard

483 counterfactual comparisons under the potential outcomes model. The promise of first-generation 484 causal knowledge has historically been that, despite everything it lacks, it suggests a target that

485 can be manipulated to change the probability of an outcome on a large scale (Gueron \& Rolston, 486 2013). Because we know that lithium treatment causes an average difference in manic

487 symptoms, we can prescribe lithium to as many bipolar patients as possible in the hopes of 488 reducing the severity of manic symptoms in as many people as possible, even if we lack a clear 489 sense of who is most likely to benefit from this treatment or how this causal relationship comes 490 about.

492 And yet, for all the difference that lithium has made, not knowing exactly how or for whom this 493 treatment works has limited its utility. Lithium is effective in fewer than one in three patients 494 and, even after seventy years of research, its mechanisms of action remain largely undefined 495 (Alda, 2015; Harrison et al., 2015).

497 Lithium is far from the only intervention with a positive average treatment effect, high 498 heterogeneity in its effects, and unclear mechanism(s) of action. As a result, scientists have 499 become increasingly vocal about the limitations of first-generation causal knowledge (Bailey et 500 al., 2020). In the behavioral and social sciences, as seminal findings have failed to replicate, 
501 generalize, and sustain over time, scholars have criticized "the narrow emphasis on discovering

502 main effects and the common practice of drawing inferences about an intervention's likely effect

503 at a population scale based on findings in haphazard convenience samples that cannot support

504 such generalizations." (Bryan, Tipton, \& Yeager, 2021, pp. 1). If social science is to advance and

505 reach more people, we need to "revolutionize" our approach to identifying and applying causal

506 knowledge (Bryan, Tipton, \& Yeager, 2021, pp. 1).

507

508 In many corners of science, this revolution has already started. Once again, we can look to

509 lithium treatment for guidance. Knowing that lithium creates an average difference in manic

510 symptoms is useful not only because it identifies an intervention target, but also because it

511 identifies a causal pathway that can be explored to better understand the pathophysiology of

512 bipolar disorder and sources of heterogeneity in its treatment. For example, recent research has

513 found that variation in properties of neuronal signaling explain differences in response to lithium

514 (Mertens, 2015). In particular, lithium responders show a reduction in the hyperexcitability of

515 hippocampal dentate gyrus neurons, suggesting that this "might be the mechanism that allows

516 [lithium] to improve symptoms in both mania and depression phases.” (Stern et al., 2018, pp.

517 1461). With this knowledge, these researchers have been able to accurately predict who will

518 respond to lithium, to test whether alternate treatments reduce neuronal hyperexcitability in

519 lithium non-responders, and to discover highly-specific electrophysiological processes that serve

520 as candidates for pharmacological intervention (Stern et al., 2018; Santos et al., 2021).

522 All of this followed from the first-generation knowledge that lithium makes an average

523 difference in symptoms of mania. By continuing to investigate this causal pathway, we have 
524 been able to migrate our relatively shallow understanding of this causal effect to a position of

525 greater causal depth. These types of investigations represent a progression toward what we refer

526 to as second-generation causal knowledge. This is knowledge that provides a "clear sense of the

527 mechanisms of change through which effects (intended and unintended) occur, which specific

528 [causal] components and combinations are likely to be most (and least) effective, and in what

529 contexts and with whom such effects will potentially be replicable.” (Bonell et al., 2012, pp. 10).

530 The promise of second-generation causal knowledge is that, by identifying processes and

531 contexts through which the effect emerges, we will be able to increase uniformity, improve

532 understanding, and isolate steps in the causal path that serve as candidates for intervention.

\section{$534 \quad 2.5$ Summary}

535 In this section, we discussed one of the primary tools that social scientists use to test causation:

536 RCTs. The counterfactual was introduced as the primary causal concept that gives RCTs causal

537 power, with particular emphasis placed on counterfactual situations that involve manipulation

538 and control. The construction of parallel worlds and the comparison of potential outcomes

539 across these worlds was discussed as the foundation of the average treatment effect. Guidelines

540 for interpreting average treatment effects in the context of RCTs were advanced by detailing

541 what these causal relationships are not: they are not the same across all people (uniform), they

542 are not isolable causes (unitary), and they are not explanations for how a cause changes an effect

543 (explanatory). Using the example of lithium administration, we highlighted how the

544 understanding that a cause creates an average difference in an outcome (first-generation causal

545 knowledge) is traditionally used to identify and implement large-scale intervention targets. We

546 reviewed the limitations of this application and highlighted how second-generation approaches 
547 can improve our understanding of the mechanisms of action generating an effect and sources of

548 heterogeneity in treatment outcomes. In the next section, we carry forward this experimental and 549 interpretational framework to scaffold our definition of what it means for genes to be causes. 


\section{3. Causal inference in genetic research designs}

\section{$551 \quad 3.1$ An overview of behavior genetics}

552 Tracing the causes of human behavior has been of scholarly interest since long before social 553 scientists were using RCTs to manipulate measured variables. In every epoch of documented

554 history, heredity has been considered one such source of human action and decision-making (see 555 Loehlin, 2009 for a complete history of behavior genetics). It was only relatively recently, 556 however, that two major breakthroughs transformed this longstanding endeavor from speculation 557 to quantification. The first came in 1869, when Francis Galton redefined the study of heredity as 558 the study of measurable similarities between relatives (Galton, 1869; Kevles, 1995). Then in 559 2001, researchers successfully sequenced the human genome, making it possible to observe the 560 composition of human DNA (Venter et al., 2001). These empirical milestones have provided 561 critical scientific insight into the etiology of complex human outcomes, and it turns out that the 562 pre-empirical scholars were right: genes do cause human behavior. Arriving at this conclusion, 563 however, requires more than simply obtaining estimates of genetic associations. Once again, "no 564 causes in, no causes out."

566 These methodological advances have formed the foundation of the two principal methodologies 567 used in behavior genetics: twin studies and genome-wide association studies (GWASs). In twin 568 studies, pairs of monozygotic twins, sharing $100 \%$ of their segregating genetic variance ${ }^{2}$, are 569 contrasted with pairs of dizygotic twins, who share only 50\%. The total variance of a measured 570 trait can then be decomposed into three latent sources: additive genetic variance $\left(\mathrm{a}^{2}\right)$, shared 571 environmental variance $\left(\mathrm{c}^{2}\right)$, and nonshared environmental variance ( $\left.\mathrm{e}^{2}\right)$ (Plomin, DeFries, 572 Knopik, \& Neiderhiser, 2013). Of primary interest to behavior geneticists is the proportion of 
573 phenotypic variance attributable to additive genetic variance, also known as a trait's heritability

$574\left(\mathrm{~h}^{2}\right)$. Like an $R^{2}$ effect size, heritability is useful in that it quantifies the extent to which

575 phenotypic differences are statistically accounted for by genetic differences (writ large), but it

576 fails to specify which genes or, crucially, how those genes are responsible for producing

577 phenotypic differences. Without such mechanistic knowledge, it can be difficult or impossible to

578 predict whether genetic influences will be portable across environmental contexts (Uchiyama,

579 Spicer, \& Muthukrishna, 2021; Mostafavi et al., 2020).

581 The breakthrough in genetic sequencing modernized the estimation of genetic associations from

582 a single unobserved variable to millions of observed variables. In GWAS, individual genetic

583 sites (known as single nucleotide polymorphisms (SNPs)) are entered as independent variables in

584 a linear regression predicting a measured phenotype. This hypothesis-free approach tests

585 associations with millions of SNPs in order to glean insight about which specific portions of the

586 genome are associated with the occurrence or degree of a trait (Corvin, Craddock, \& Sullivan,

587 2010; see Box 1 for a technical primer on GWAS).

589 The estimates from these linear regressions, called SNP effect sizes, represent either the

590 probability that cases differ from controls at a particular genetic site or represent the magnitude

591 of the association between a particular genetic site and a continuous outcome. The entire set of

592 SNP effects (collectively referred to as summary statistics) are in turn used for a wide array of

593 applications. A popular application in the social sciences is using GWAS summary statistics to

594 create a polygenic score, which aggregates information from all SNPs into a single index of each

595 individual's genetic propensity for a trait (Sugrue \& Desikan, 2019). 
596 Box 1. Primer on GWAS. Single nucleotide polymorphisms (SNPS) are the sites of DNA that 597 commonly vary in the population $(>1 \%)$. Each SNP is composed of a pair of allelic variants, or 598 two of four possible genetic "letters" (adenine, thymine, cytosine, and guanine). SNP genotyping 599 identifies each genotyped individual's pair of allelic variants at each polymorphic site (Perkel, 600 2008). Due to the correlation structure amongst SNPs (known as their linkage disequilibrium), it 601 is possible to impute values for hundreds of SNPs not measured during the genotyping process, 602 allowing for the analysis of millions of genetic variants in relation to an outcome. Prior to 603 conducting GWAS, the raw allelic structure of each SNP is converted to an ordinal variable 604 reflecting the number of minor alleles (i.e., the less commonly occurring allele in the population) 605 that an individual possesses. The number of minor alleles at each SNP is what is then associated 606 with the outcome to obtain a SNP effect size. SNP effect sizes are used for a growing number of 607 applications, including annotating the biological function of identified SNPs (Watanabe,

608 Taskesen, van Bochoven, \& Posthuma, 2017), constructing polygenic scores (Sugrue \& Desikan, 609 2019), modeling genetic associations with other traits (Grotzinger et al., 2019), and estimating 610 SNP-based heritability (Yang, Zeng, Goddard, Wray, \& Visscher, 2017). 
611 Exactly what $\mathrm{h}^{2}$ estimates and SNP associations tell us about the relationship between genes and

612 behavior has been the source of much discourse and much disagreement (see Figure 1). At one

613 end of the spectrum are those that claim - quite extraordinarily - that these coefficients prove

614 that traits like intelligence are genetically determined and that differences in ability between

615 racial and ethnic groups must be the result of hardwired genetic differences (Jensen, 1969;

616 Herrnstein \& Murray, 1996; Murray, 2020). At the other end are those that claim that, not only

617 do these coefficients fail to represent genetic determinism or innate group differences, they fail

618 to represent anything meaningful about how genes influence behavior (Block, 1995; Lewontin,

619 1974).

621 Both extremist views are mistaken. $\mathrm{H}^{2}$ estimates and SNP effects are neither supra-causal nor

622 inherently meaningless. They are simply point estimates from statistical models. In the same way

623 that a statistical association between cannabis use and psychotic symptoms would not imply that

624 cannabis use is the ultimate or fixed source of psychosis, nor that a population with a high

625 incidence of psychosis must therefore be using more cannabis, $\mathrm{h}^{2}$ estimates and SNP effects

626 imply neither deterministic associations nor between-group differences. What can be implied,

627 however, is that using cannabis potentially increases risk for developing psychotic symptoms.

628 This is a causal hypothesis that must be evaluated using study designs, like RCTs, that

629 appropriately instantiate causal concepts. Likewise, most behavior geneticists believe that twin

630 studies and GWAS have utility in identifying genetic factors that potentially predispose for

631 phenotypic differences between people (Visscher, Hill, \& Wray, 2008).

632 
633 But if the conclusion that we aim to defend is that genes cause behavioral and psychological

634 outcomes, then clearly, we need something more than genetic associations alone. For genes to be

635 considered causes, $\mathrm{h}^{2}$ estimates and SNP effects need to be bolstered by the same causal concepts

636 that privilege $t$-statistics as ATEs. We need to know what the trait would have looked like if the

637 genotype had been different. Unlike in RCTs, however, we cannot manipulate the treatment to

638 simulate the counterfactual. We cannot randomly assign people to receive a certain genotype - at

639 least not in any agreeable, ethical, or disseminable way. Fortunately, there is no need. The

640 counterfactual has already been simulated for us.

641

\section{$642 \quad 3.2$ The natural experiment of genetic inheritance}

643 Consider this portentous lesson from history. In the fall of 1918, an influenza pandemic hit the

644 United States without warning. By January of 1919, the virus had mostly disappeared. This

645 meant that babies born just a few months apart experienced vastly different prenatal conditions.

646 In effect, the virus had manipulated the prenatal environment, randomizing adjacent birth cohorts

647 into those exposed to pandemic conditions - including either the flu itself or related stressors -

648 and those experiencing relatively normal, or control, conditions. These cohorts represented

649 parallel worlds that could be compared at different developmental stages to examine the causal

650 effect of prenatal conditions on economic outcomes. Leveraging this natural randomization to

651 simulate conventional RCT methodology, researchers concluded that in utero exposure to

652 pandemic conditions caused lower educational attainment, lower income, and lower

653 socioeconomic status in adulthood (Almond, 2006). The real-world generation of these

654 counterfactual conditions typifies a natural experiment, in which treatment and control groups

655 are meted out on the basis of a naturally-occurring randomization mechanism. 
657 In the case of genes, counterfactual conditions are created through meiosis, an instance of 658 naturally-occurring biological randomization. Meiosis is a process of cell division and DNA 659 recombination that results in the production of unique sex cells (i.e., gametes). This process is 660 essentially a natural manipulation of parental DNA. During recombination, segments of DNA

661 from identical (i.e., homologous) chromosomes cross over in novel patterns to create new 662 chromosomes to be inherited by offspring. Recombination is a primary source of 663 intergenerational genetic variation (Nachman, 2002; Spencer et al., 2006), and the amount of

664 variation created is vast. Within a single person, recombination results in the production of over 6658 million unique chromosomal combinations (Batmanian, Ridge, \& Worrall, 2011). When 666 combined with a partner's gametes, there are over 70 trillion genotypes that an offspring could 667 become (Carroll, 2020) - over 70 trillion potential treatment conditions.

669 Manipulation is not synonymous with randomization, however. If the variation produced by 670 meiosis creates trillions of different treatment conditions, it must also be the case that the 671 inheritance, or assignment, of these conditions is random. Two principles established by $19^{\text {th }}$ 672 century geneticist Gregor Mendel reassure us of the validity of randomization: (1) the Law of

673 Segregation states that at every point in the genome, offspring randomly inherit one allele from 674 each parent and (2) the Law of Independent Assortment states that alleles will segregate to 675 gametes independently of one another (Davies et al., 2019). What this means is that at each 676 genetic site, you inherit two alleles (one from your mother and one from your father) but which

677 alleles you inherit is a completely random event ${ }^{3}$. This randomness gives genetic inheritance its 678 experimental infrastructure (Davey Smith \& Ebrahim, 2003). It allows us to compare family 
679 members' genes to examine what would have happened if they had received a different

680 genotype. Confidence in these counterfactual conditions, however, depends on how well they

681 meet those four critical assumptions of all randomized experiments - independence, sample

682 homogeneity, potential exposability, and SUTVA.

684 3.2.1. Independence. At face value, Mendel's laws satisfy the independence assumption. If 685 genetic variants are randomly and independently assigned, then we should expect no systematic 686 dependency between genotype and outcome (Holland, 1988). In actuality, there exist several 687 such sources of dependency in a population. Due to evolutionary factors and non-random mating 688 patterns, different subpopulations, such as those with different ancestral backgrounds, have 689 different frequencies of certain alleles, known as population stratification (Cardon \& Palmer, 690 2003). Discrepancies in allele frequency across different groups of people are often

691 systematically associated with environmental differences (environmental confounding), non692 ancestral-related genetic differences (genetic confounding), and mate selection (assortative693 mating confounding) (Young, Benonisdottir, Przeworski, \& Kong, 2019). This means that if we 694 estimate a genetic association in a randomly-selected sample from the population, we cannot 695 separate the causal effect of the gene from any of these confounding sources. Conventional 696 GWASs do their best to mitigate these problems. For instance, they are conducted in ancestrally 697 homogeneous samples (Mills \& Rahal, 2019). Even within these samples, population 698 stratification is often corrected for by controlling for ancestry-based principal components (Price 699 et al., 2006) or using linear mixed models (Yang, Zaitlen, Goddard, Visscher, \& Price, 2014), but 700 none of these practices guarantees independence (Haworth et al., 2019). 
702 The only way to satisfy independence is to examine genetic associations relative to parental

703 genotypes, for example, by directly comparing an offspring to both of its parents or by

704 comparing siblings from the same family (Brumpton et al., 2020; Young et al., 2018). For any

705 individual, "each of the meiosis and conception events that determined [a person's] DNA is an

706 independent event conditional on the parental genotypes.” (Davies et al., 2019, pp. R174,

707 emphasis added). Here are Mendel's laws in action: the genotype of any individual is a random

708 and independent selection of genes from their parents. Because siblings inherit their genes from

709 the same pool of potential genotypes, the pitfalls of population structure can be avoided if the

710 comparison of siblings is appropriately conditioned on their parental genotypes (Zaidi \&

711 Mathieson, 2020; Fletcher, Wu, Li, \& Lu, 2021). Novel designs like within-sibship GWAS and

712 relatedness disequilibrium regression can help ensure that randomization in meiosis functions the

713 same way it does in RCTs, by rendering treatment assignment and outcome independent (Howe

714 et al., 2021; Young et al., 2018).

715

716 3.2.2. Sample homogeneity. Comparing members of the same family should allow

717 randomization to serve another one of its chief functions: preserving sample homogeneity

718 (Rubin, 1974). Randomization "guarantees, by construction,...that the [difference in means for

719 all other causes] is zero in expectation" (Deaton \& Cartwright, 2018, pp. 4). In practice, sample

720 homogeneity is a function of two factors: (1) the number of participants and (2) the number of

721 trials (Deaton \& Cartwright, 2018). GWASs are uniquely suited to address these factors. First,

722 standard GWAS sample sizes tend to tally in the millions (e.g., Karlsson Linnér et al., 2019;

723 Nielsen et al., 2018; Evangelou et al., 2018), orders of magnitude larger than typical RCTs.

724 Though improving the sample sizes of within-family designs remains a critical aim of behavior 
725 genetics, recent studies have begun to analyze SNP effects in upward of 40,000 sibling pairs

726 (Karlsson Linnér et al., 2021). Second, meiosis is essentially a series of millions of randomized

727 trials. Since the assortment of alleles at each genetic site is a random event, we should have

728 increasing confidence that allele carriers do not differ in systematic ways as we aggregate over

729 the genome. This makes summary indices of genetic effects, like polygenic scores, particularly

730 powerful tools.

731

732 3.2.3. Potential exposability. Potential exposability is directly related to manipulability. If the

733 treatment is something that can be manipulated, or changed, then randomization ensures that

734 every participant is potentially exposable to any condition (Jo \& Muthén, 2001). In one sense,

735 the conditions of meiosis easily satisfy the requirement of potential exposability. Meiosis

736 manipulates parental DNA, creating trillions of unique genotypes for an offspring to inherit

737 (Carroll, 2001). The fact that meiosis satisfies genotype-level exposability suggests that, as with

738 sample homogeneity, indices that aggregate across the genome may be particularly suited for

739 causal inference.

741 3.2.4. SUTVA. Consider a family with two adolescent children, Linda and Maggie. Through

742 meiosis, Linda and Maggie were randomly assigned their genotypes, creating parallel worlds that

743 could be compared to examine whether their genes caused different life outcomes. In particular,

744 Linda inherits variants in the ADH1B gene that affect her metabolism of alcohol, contributing to

745 her refraining from alcohol use (Bierut, 2011). Linda's substance use choices become part of the

746 environment that she shares with Maggie, a factor that often serves to align substance use habits

747 amongst siblings (see Samek, McGue, Keyes, \& Iacono, 2015 for review of shared 
748 environmental factors in substance use). If observing Linda decline alcohol, return home

749 promptly before curfew, and engage in substance-free recreational activities influences Maggie's

750 alcohol-related behavior, then SUTVA has been violated. Linda's treatment assignment - her

751 genotype - has interfered with Maggie's potential outcome, obfuscating a causal comparison of

752 counterfactual conditions (Rubin, 1980). For SUTVA to be preserved in the natural experiment

753 of genetic inheritance, there can be no indirect sibling-to-sibling genetic effects (Eaves, 1976).

755 The surest way to safeguard against the behavioral transmission of genetic effects between

756 siblings is to analyze data from a single offspring controlling for both of the parental genotypes.

757 Alternatively, one could compare the potential outcomes of siblings who were not raised together

758 (e.g., adoption studies; Plomin, DeFries, \& Loehlin, 1977). This assures that each sibling's

759 genotype has as little influence on the other sibling's phenotype as possible. To be sure, even

760 adoption studies cannot protect against other sources of indirect genetic effects (see Scarr \&

761 McCartney, 1983 for review), but these are more a problem of sample homogeneity than

762 SUTVA. As an analogy, consider an RCT on a pharmacological treatment of depression. If some

763 participants happen to read existential philosophy during their treatment, the threat is that a

764 potential imbalance of philosophy readers across treatment groups will confound depression

765 scores. Reading existential philosophy, however, has nothing to do with whether the depression

766 treatment that one participant receives interacts with another participant's depressive symptoms.

767 Non-sibling indirect genetic effects are like reading existential philosophy - they are sure to

768 affect an offspring's outcome, and they might create a systematic difference in (genetically-

769 influenced) environments across allele carriers, but they do not violate SUTVA. 
771 Evidence has begun to suggest, however, that when siblings are raised together, their respective

772 genotypes do in fact influence their siblings' phenotypes (Fletcher, Wu, Zhao, \& Lu, 2020). The

773 presence of sibling interference need not undo causal inference entirely (Rosenbaum, 2007). In

774 these cases, addressing SUTVA involves determining (a) the direction of the interference and (b)

775 the magnitude of the effect. Developmental psychologists differentiate between imitation and

776 contrast effects - those patterns of "behavioral acquisition via social learning" that serve to either

777 fuse or drive apart sibling behavior (Carey, 1986, pp. 320; see Dolan, de Kort, van Beijsterveldt,

778 Bartels, \& Boomsma, 2014 \& Moscati, Verhulst, McKee, Silberg, \& Eaves, 2018 for empirical

779 demonstrations). Whether or not Linda refraining from alcohol use causes Maggie to similarly

780 abstain or rebel into greater use depends on factors like their relative ages (Abramovitch, Corter,

$781 \&$ Lando, 1979) and the stage of their dyadic relationship (Carey, 1986).

782

783 Empirically examining SUTVA involves quantifying the magnitude of imitation or contrast

784 effects by segregating the direct causal effect from interference effects. This can be achieved

785 through a process of triangulation (Lawlor, Tilling, \& Davey Smith, 2017), a leveraging of

786 multiple data sources and unique methodological approaches to increase confidence in a causal

787 conclusion. In the case of sibling interference, Kong et al. (2018) provide a paradigmatic

788 example: using genotype data from both siblings and parents and integrating within-sibship

789 comparison with a traditional trio design (see Connolly \& Heron, 2015 for review), the

790 researchers were able to triangulate on a direct causal estimate of genotype on outcome. By

791 including the effect of the sibling's genotype and the uninherited portions of the parental

792 genotypes in the model, Kong et al. (2018) estimated the magnitude of the interference and

793 effectively ensured that it, and other confounding sources, were controlled for. Adoption studies 
794 may ensure protection against SUTVA violations, but innovative methodological approaches can

795 still rescue causal inference in the face of sibling interference.

\subsection{The shallow end of genetic causation}

798 Perhaps no outcome has been more magnetic in contemporary behavior genetics than educational 799 attainment (EA; Martin, 2018). The most recent GWAS of EA, published in 2018, has already 800 been cited over 900 times (Lee et al., 2018). It has also generated a litany of passionate critiques

801 and rebuttals (see, for example, the blog post titled "Why We Shouldn't Embrace the Genetics of 802 Education"; Warner, 2018). Yet prior to 2013, EA was considered a fairly rudimentary, albeit 803 important, covariate in GWAS (Plomin \& von Stumm, 2018). Priority had previously been given 804 to medical and psychiatric disease states - EA was simply a confound to rule out. As GWAS 805 methodology began to permeate the social sciences, however, the troves of data on EA that had 806 been accrued over the years by large-scale research consortia became invaluable. Suddenly, EA 807 had become the most GWAS-able trait.

809 The first GWAS of EA detected three SNPs with significant effects in 126,559 individuals, 810 collectively explaining $2 \%$ of its variance (Rietveld et al., 2013). Three years later, 74 SNPs

811 were detected in twice as many people, explaining $4 \%$ of the variance (Okbay et al., 2016). By

812 2018, the GWAS of EA included 1.1 million individuals, over 1000 significant SNP effects, and 813 explained over $10 \%$ of the variance (Lee et al., 2018). By social science standards, that is a large 814 and stable effect size (Funder \& Ozer, 2019), and one that even outperforms many complex, 815 multivariate approaches to predicting educational outcomes (Salganik et al., 2020). The 816 incremental successes of the EA GWASs are undeniably impressive, but they have not been 817 accompanied by incremental increases in causal inference. Even if the fourth iteration of the EA 
818 GWAS detected 5000 significant SNP effects and explained 50\% of the variance in EA, it alone

819 would not move us closer to the conclusion that genes cause educational outcomes.

821 To be sure, we are currently in a position to conclude that genes cause EA. But this conclusion is 822 only possible because researchers have applied summary statistics from EA GWASs to datasets

823 that allow for counterfactual comparison. By using "within-family genetic design[s]", differences

824 in associations between polygenic scores and educational outcomes allow for "causal inference

825 and explanation" (Selzam et al., 2019, pp. 360). So when we find that "children with higher 826 polygenic scores...move up the social ladder in terms of education, occupation, and wealth, even

827 compared with siblings in their own family" (Belsky et al., 2018, pp. E7281), the appropriate 828 conclusion is that genes cause these differences in attainment.

830 For behavior geneticists, this is undoubtedly a triumph. After years of null results and

831 unreplicable false positives, the field can now construct measures of DNA differences that cause

832 important life outcomes. For others, however, this statement rouses ambivalence at best, and

833 outrage at worst. There is a vocal contingent of bloggers, journalists, and scientists who fear that

834 GWAS of social outcomes and its associated applications "will only be fuel for those who think

835 that social inequalities are natural and unchangeable" (Samorodnitsky, 2020, para. 20). Such a

836 picture of genetic causes is entirely unwarranted when we remember what it means for

837 something to be a cause: non-uniform, non-unitary, and non-explanatory.

839 It can be easy to neglect that genetic causes behave just like ATEs from RCTs. Prominent 840 examples from medicine have shaped expectations that genes are of a different class of causes 
841 (Ross, 2019). Take cystic fibrosis (CF), for example. CF is an autosomal recessive disorder

842 present in about 70,000 individuals globally. It is caused by two mutated copies of the cystic

843 fibrosis transmembrane regulatory $(C F T R)$ gene on the $7^{\text {th }}$ chromosome (Cutting, 2015). Unlike

844 most ATEs, this genetic cause is (a) uniform - it consistently produces the occurrence of CF

845 across individuals, (b) unitary - it alone causes the occurrence of $\mathrm{CF}$, and (c) explanatory - it

846 provides an explanation for how $\mathrm{CF}_{\text {occurs }}^{4}$ (Elborn, 2016). Together, these characteristics make

847 CF an instance of deep genetic causation ${ }^{5}$ (see Turkheimer, 1998 on strong biologisim; Meehl,

8481972 on specific genetic etiology). Scientists gravitate toward deep causes. They are salient,

849 simplistic, and they provide a coherent framework for the operation of a complex system like the

850 genome (Engel, 1977; Kendler, 2005). Despite the conceptual attraction to deep causes, almost

851 everything we have learned from GWAS points to genes as shallow causes - many variants from

852 across the genome relate to behavioral outcomes, but when they matter and how they matter

853 differs across people, place, and time (Ross, 2019). The appropriate paradigm for genetic causes

854 of human behavior is therefore not the deeply-deterministic example of CF, but the local,

855 probabilistic, and distal characteristics of ATEs.

857 Support for the idea that genes are non-unitary causes of behavior is so robust that it has been 858 consecrated as one of the modern laws of behavior genetics (Chabris, Lee, Cesarini, Benjamin, \& 859 Laibson, 2015). Indeed, arguably the greatest takeaway from the GWAS era has been that 860 individual genetic variants do not produce behavioral effects on their own. This is not a trivial 861 statement - decades of research were spent hunting for single polymorphisms (i.e., candidate 862 genes) that would prove to have causal control in the etiology of behavioral and psychological 863 outcomes (see Munafò, 2006 for overview). Consistent failure of these findings to replicate, 
864 however, pushed behavior geneticists to develop more sophisticated models. Most believe now

865 that the genetic architecture of complex traits is polygenic (involving thousands of variants with

866 small effects distributed throughout the genome (Duncan, Ostacher, \& Ballon, 2019)) or even

867 omnigenic (involving sundry genome-wide variants that affect behavior by disrupting

868 interconnected gene regulatory networks (Boyle, Li, \& Pritchard, 2017)). But if single genes are

869 not unitary causes of behavior, neither is the genome writ large. Even a model that considered

870 every gene in the genome and its higher-order function would fail to be causally exclusive

871 because it would fail to account for larger etiological systems like "history and cohort, the life

872 course, and social structures like gender" through which "genetic influence must be understood"

873 (Herd et al., 2019, pp. 1070). Genes might cause EA, but they are certainly not the only cause of

874 EA.

875

876 The nesting of genetic effects within biological, psychological, and social systems is what makes

877 them local parameters. The size and shape of a particular effect will always depend on the size

878 and shape of the other causal factors present in that instance. In theory, this suggests that genetic

879 effects will be non-uniform. If context matters, then genetic effects should change across

880 settings. Nevertheless, there persists "the common assumption...that genetic effects are

881 'universal' across environments.” (Tropf et al., 2017, pp. 758). This would imply that genetic

882 effects are deterministic, that they will produce the same effect in the same way every time,

883 independent of the context. Two takeaways from modern genomics suggest that this assumption

884 is unfounded: (1) genetic effects are heterogeneous across environments and (2) genetic effects

885 show poor generalizability.

886 
887 That genetic effects vary across environments is a proposition of longstanding tenacity (gene $x$

888 environment (GxE) interactions) (see Jaffee \& Price, 2007 for a review; Feldman \& Lewontin,

889 1975; Turkheimer \& Gottesman, 1996). Reliably identifying such interactions, however, has

890 historically proved difficult (Munafò \& Flint, 2009). This is where the substantial increases in

891 the predictive power of GWASs, like those seen in EA, have considerable value. Several studies

892 have been able to provide insight into the environments that facilitate the emergence of genetic

893 effects on EA. Genetic effects appear to increase in size when structural barriers like gender

894 (Herd et al., 2019), class (Rimfeld et al., 2018), and intergenerational mobility (Engzell \& Tropf,

895 2019) are removed. Said differently, the probability that genes matter for EA varies depending

896 on the environmental exposures of the individual. Similar heterogeneity has been observed in

897 genetic effects on reproductive, physical, and psychiatric outcomes (Coleman et al., 2020; Tropf

898 et al., 2017).

899

900 The disparity in genetic effects across environments is further corroborated by the fact that

901 GWAS findings have largely failed to be applicable outside of discovery samples. That means

902 that the genes that predict an outcome in one sample fare poorly in predicting the same outcome

903 in a separate sample. Not only is this the case when testing predictive accuracy in diverse

904 populations (Martin et al., 2017), but inconsistent accuracy has also been found when looking

905 within demographic subgroups (i.e., age, gender, socioeconomic status) of the same ancestry

906 (Mostafavi et al., 2020). Moreover, this failure for genetic effects to port was found even when

907 phenotypes were measured consistently across samples. Variation in the measurement or

908 applicability of a phenotype across populations, for example when "educational attainment

909 emphasizes rote memorization or formal writing... [rather than] experiential learning”, is likely 
910 to be another source of restricted generalizability (Meyer, Turley, \& Benjamin, 2020, para. 5).

911 Collectively, this suggests that while genes cause EA, this is neither a singular nor a generic

912 claim (Cartwright, 1988). We know neither that genes are the cause of EA for a specific

913 individual nor that genes are the cause of EA for all people across place and time.

914

915 Genes, however, do have generic functions (Dawkins, 1982). Every gene produces biochemical

916 material for cellular encoding, and the specific set of instructions governed by a particular gene

917 is consistent across person, place, and time (Schaefer \& Thompson, 2014). This would indicate

918 that the first step in the causal pathway from genes to behavior is uniform. To ultimately arrive at

919 non-uniform effects on behavior, there must therefore be subsequent points along this causal

920 pathway where people diverge. Indeed, we know already that this divergence begins almost

921 immediately after gene function. Even processes like gene expression and gene regulation show

922 substantial heterogeneity across environments (Bork et al., 1998), and this tends to be more the

923 rule than the exception as the pathway winds through biological (Gough et al., 2017),

924 psychological (Molenaar, 2004), and sociological systems (Scott, 1988). Each point of

925 heterogeneity demarcates a garden offorking paths (Borges, 1941/2018; Gelman \& Loken,

926 2014), a splintering of a uniform stream of processes into separable causal pathways. The

927 staggering amount of heterogeneity that exists in the processes that extend from genes to

928 behavior tells us that there are a potentially untraceable number of causal pathways. Identifying a

929 genetic cause provides no insight into which causal pathway ultimately produced the behavior

930 because genetic causes are not mechanisms. Genes might cause EA in the sense that genes made

931 some distal difference in level of attainment, but not in the sense that they provide an

932 explanation for how this difference was made. 
934 This distinction between causes and mechanisms often gets lost when applied to the relationship

935 between biology and behavior (Thomas \& Sharp, 2019). As Gregory Miller writes, "[r]elevant

936 science abounds with demonstrations that...imply causal relationships between psychology and

937 biology...yet we often write as if we know the mechanisms" (Miller, 2010, pp. 717). Despite the

938 implicit assumption that biology reveals something inherently mechanistic, there is nothing that

939 necessitates that biological causes need be mechanistic nor that mechanisms need be biological.

940 In plainest terms, mechanisms explain an effect. Even putatively biological associations, like

941 genetic effects on lung cancer, might be largely explained via social processes, like access to

942 cigarettes (Kendler et al., 2012). Further, whether a biological cause actually provides

943 explanatory insight is a matter of circumstance. Consider the example from Eric Turkheimer

944 (1998) on the origins of vocal muteness for two individuals, one who has suffered a stroke in

945 Broca's area of the brain and the other who has taken a religious vow of silence:

“It seems natural to describe the stroke patient's muteness as biological and the monk's as psychological. What do these attributions mean? It is not simply that the aphasia is "in" the

953 In other words, the key difference is that only the aphasia patient's identified biological cause is

954 mechanistic: it describes how a localized lesion compromises the neural areas that support

955 linguistic functioning - an outcome that would also happen to be invariant across time and place. 
956 Likewise, biology factors into the monk's muteness (see, for example, research on the neural

957 networks supporting religiosity; Kapogiannis et al., 2009), but any identified biological cause

958 would be insufficient to explain his vow of silence. The mechanism behind the monk's silence is

959 psychological - it is his decision that generates and explains his outcome.

\subsection{Using genetic causes to advance second-generation causal knowledge}

962 In this paper, we have argued for the idea that certain types of genetic effects (i.e., contingent on

963 parental genotypes) constitute first-generation causal knowledge. Like average treatment effects,

964 genes are causal in the sense that "differences in [genotype]...cause phenotypic differences in

965 particular genetic and environmental contexts" (Waters, 2007, pp. 558). Unlike with many

966 average treatment effects, however, this information cannot be used to manipulate the causal

967 variable on a population scale. This would seem to limit the applied value of identifying and

968 conceptualizing genes - or any other immutable cause - as average difference-makers. But, as

969 the case of lithium treatment showed us, there is no reason to restrict first-generation causal

970 knowledge to this singular application. Like all first-generation causes, genetic effects contingent

971 on parental genotypes represent causal pathways that can be explored to advance second-

972 generation aims.

973

974 If we accept the conclusion that genetic variants make an average difference in psychological

975 and behavioral outcomes, then we can begin to embrace the trove of potential scientific

976 discoveries lying along this casually distal pathway. To start, we can improve phenotypic

977 understanding by exploring mediating processes. Traditionally, researchers have used GWAS

978 results to gain deeper insights into the biology of complex behavioral outcomes (Dick et al., 
979 2018). Approaches like bioinformatics annotation make it possible to locate specific cells,

980 tissues, and organs where relevant genetic variants are expressed (Watanabe et al., 2019). In

981 pathway analysis, genetic variants are clustered by functional relatedness and used to assess

982 whether candidate biological functions are implicated in disease etiology (White et al., 2018).

983 Collectively, these techniques serve to "increase explanatory power" by specifying the

984 "parameters of the nervous system [that] are aberrant as a result close in the causal chain to the

985 gene or genes” (Khatri, Sirota, \& Butte, 2012, pp. 1; Meehl, 1972, pp. 11).

986

987 Inspired by this method of biological discovery, researchers have called for an approach that

988 maps genotypes to multifarious aspects of the social environment (phenotypic annotation;

989 Belsky \& Harden, 2019). By associating polygenic scores for one phenotype with related

990 phenotypes at different stages across the lifespan, we can detail potential behavioral and

991 developmental pathways through which target phenotypes emerge. Already this work has

992 provided considerable insight into how genetic risk for adult outcomes like body mass index,

993 smoking, educational attainment, and attention-deficit/hyperactivity disorder manifests in

994 childhood and adolescence (Belsky et al., 2012; Belsky et al., 2013; Belsky et al., 2016; Agnew-

995 Blais et al., 2021). Uncovering more about the biological and behavioral intermediaries bridging

996 genes and behavior improves our ability to develop integrated causal models of complex

997 behavioral phenomena.

998

999 As our understanding of the causal structure of psychological and behavioral phenotypes

1000 deepens, our discovery of potential prevention and intervention targets improves (Dick, 2018).

1001 Indeed, each process that we find mediates cause and effect represents a candidate for 
1002 intervention, even if the original cause itself is immutable. Consider again the example of lithium

1003 administration: researchers localized the differential pattern of neuronal signaling in lithium

1004 responders and non-responders to the expression of a single gene (LEF1) (Santos et al., 2021).

1005 Rather than structurally alter the gene, these researchers explored its downstream biological

1006 consequences (e.g., transcription pathways), thereby identifying "useful phenotypes for drug

1007 development." (Santos et al., 2021 pp. 12). In these cases, the relevant question is not just

1008 whether the cause itself is manipulatable, but (a) which of the mediating processes are

1009 manipulatable and (b) which processes' manipulation will generate a meaningful effect on the

1010 outcome. Knowing that $L E F 1$ causes differences in brain signatures characteristic of lithium

1011 response allows us to identify mechanistic processes that could be pushed upon to improve

1012 treatment responsivity.

1013

1014 The same should be true of behavioral and health-related outcomes. Understanding how genetic

1015 factors unfold along biological and behavioral pathways across development allows us to isolate

1016 intermediate processes that represent (a) prognostic markers of future outcomes and (b) targets

1017 for programmatic manipulation that may serve to close the gap in health disparities (Belsky,

1018 Moffitt, \& Caspi, 2013). Behavioral genetics is beginning to turn toward these applications, and

1019 research on body mass index (BMI) provides a ready example. Large-scale phenotypic

1020 annotation efforts have begun to link genetic variants associated with adult BMI to eating

1021 behaviors in childhood and adolescence (Herle et al., 2021; Abdulkadir et al., 2020). These

1022 studies have found that, by as early as age two, a child's eating behavior may demarcate genetic

1023 risk for adult BMI. This suggests that eating habits, and possibly related health behaviors, may

1024 represent malleable outcomes through which we can mitigate the influence of genetic differences 
1025 on BMI. Preliminary evidence supports this claim. Correlational research has shown that genetic

1026 effects on adult BMI are larger in individuals who live sedentary lifestyles and consume more

1027 sweetened beverages (Li et al., 2010; Qi et al., 2012). Early experimental findings point toward

1028 physical activity at age-11 as a modifiable behavior for attenuating the association between

1029 genes and BMI (Herle, Pickles, \& de Stavola, 2021).

1030

1031 Still, we know that not all eleven-year-olds will respond equally to a behavioral intervention.

1032 This was one of the main takeaways from the High/Scope Perry Preschool Program (HPPP) that

1033 we reviewed at the beginning of this paper. Simply being exposed to an intervention does not

1034 entail how a given person will respond, for how long the effect will last, or whether it will

1035 generalize to related behaviors across development (Bailey et al., 2020; Green, 2021; Bryan,

1036 Tipton, \& Yeager, 2021). To improve the efficacy and reach of our treatments, we need to

1037 understand the sources of individual differences in their outcomes. We need to "be concerned

1038 with the otherwise neglected interactions between organismic and treatment variables."

1039 (Cronbach, 1957, pp. 681).

1040

1041 Genetic causes can help. By integrating genomic data into longitudinal, experimental research

1042 designs, we can begin to answer causal questions about heterogeneity in treatment effects and

1043 mechanisms generating the fadeout, persistence, and emergence of those effects later in life. A

1044 growing body of work in this area has demonstrated that responses to childhood interventions

1045 like HPPP are sensitive to genetic variation (Kuo et al., 2019; Albert et al., 2015; Brody et al.,

1046 2009; Brody et al., 2013). Using the framework for genetic causation that we have advanced in

1047 this paper, we can develop more robust and comprehensive understanding of how individual 
1048 differences in constitutional factors influence treatment outcomes. In particular, we can integrate

1049 whole-genome measures from family members into two-shock designs, which yield an estimate

1050 of the interaction of two random sources of variation to provide special insight into the

1051 (biological and environmental) contexts in which a particular cause operates (Almond, Currie, \&

1052 Duque, 2017). These designs may critically advance our understanding of why particular

1053 individuals are more or less likely to respond to treatments and why particular treatment effects

1054 are more or less enduring or generalizable.

1055

$1056 \quad 3.5$ Summary

1057 In this section, we considered interpretations of the prevailing statistical parameters used in

1058 behavior genetics $-h^{2}$ and SNP effects. We argued that the randomization of offspring to

1059 genotype in meiosis generates a natural experiment, but that genetic effects on behavior can only

1060 be considered causal when other counterfactual conditions are met. The experimental

1061 assumptions of independence, sample homogeneity, potential exposability, and SUTVA were

1062 discussed with respect to genetic causation. The takeaway was that within-family designs that

1063 leverage the natural experiment of genetic inheritance are best suited for causal inference.

1064 Guidelines for conceptualizing genetic causes were examined with respect to a dimension of

1065 causal depth: deep causes, that are unitary, uniform, and explanatory, and shallow causes, that

1066 are local, probabilistic, and causally distal. We discussed how the knowledge of genetic causes

1067 as advanced in this paper can be applied to advance second-generation aims: genomic data can

1068 improve our understanding of the etiology of complex psychological and behavioral outcomes,

1069 can facilitate the discovery of intervention and prevention targets for health-related outcomes, 
1070 and can provide insight into individual differences in treatment responsivity, fadeout, and 1071 emergence. 


\section{4. Conclusions}

1073 Our motive for writing this paper was to grapple with the conceptual issues that have marked the

1074 history of behavioral genetics. To guide our discussion, we turned to philosophical and statistical

1075 thinking on the parameters for detecting and interpreting counterfactual causes. We compared

1076 the infrastructure of genetic inheritance to that of a randomized controlled trial, and concluded

1077 that genetic effects conditional on the parental genotype are causal in the same sense as average

1078 treatment effects. To conclude, we provided some suggestions for how this knowledge can be

1079 used to facilitate scientific inquiry and maximize treatment outcomes.

1080

1081 Doubtless, many will take issue with the conclusions that we have drawn and the solutions that

1082 we have offered. Such responses are understandable in a field that is so richly complex and so

1083 wildly decisive. We welcome all work that earnestly engages in, challenges, questions, or

1084 explores the ideas that we have presented in this paper, insofar as it continues to think cautiously

1085 and judiciously about the meaning and applications of genomic research. Knowledge of genetic

1086 effects on human behavior will only continue to grow over the next several decades. We must

1087 chart the course for how we interpret and utilize this knowledge. As Dov Fox wrote, "[t]here is

1088 nothing especially menacing about knowledge on its own... [a]wareness or understanding of

1089 some subject can be troubling only when those facts are sought for bad reasons, or when such

1090 data are put to bad effects." (Fox, 2018, pp. 155).

1091 


\section{Funding statement.}

1093 This work was supported by grants from the Jacobs Foundation and the John Templeton

1094 Foundation. K.P.H. is a Faculty Research Associate of the Population Research Center at the

1095 University of Texas at Austin which is supported by grant P2CHD042849 from the NICHD.

1096

1097 Conflicts of interest. None. 


\title{
1098 Endnotes.
}

\begin{abstract}
${ }^{1}$ Note that Lewis attempts to address some of these limitations by employing a similarity metric (Lewis, 1973a), which indexes the relative uniformity between two possible worlds. While this approach has been lauded for its conceptual logic, its application to the actual analysis of counterfactuals has been questioned (Bowie, 1979).
\end{abstract}

${ }^{2}$ Approximately $99.9 \%$ of DNA is identical for all humans (Collins \& McKusick, 2001). That leaves only $0.1 \%$ of the genome ( 2 million genetic variants) to differ across individuals. This sliver of genetic variation within human populations is the object of behavior genetics.

${ }^{3}$ The premise that alleles are inherited entirely independently of one another has been slightly revised since Mendel's time. Recombination preserves certain stretches of parental DNA, such that we inherit groups of alleles together (i.e., haplotype blocks) (Phillips et al., 2003). Nevertheless, Mendel's principles are just as aptly applied to haplotype blocks as to SNPs - haplotype blocks are, at least in part, randomly created (Wang, Akey, Zhang, Chakraborty, \& Jin, 2002), and inherited independently of one another (Browning \& Browning, 2011).

${ }^{4}$ The presence of two mutated copies of the CFTR gene produces an imbalance of sodium chloride to water in epithelial cells in the body. This results in the secretion of abnormally thick and sticky mucous that clogs air passages. Cardinal symptoms of cystic fibrosis include respiratory difficulties (coughing, lung infections, shortness of breath) and unusually salty sweat secretion. Diagnostic testing typically involves assessing sodium chloride levels in sweat (LeGrys, 1996).

${ }^{5}$ Importantly, shallow and deep represent poles of a dimension of causal depth. Even paradigmatically deep causes like CF possess shallow features at some level (e.g., CF is also the product of non-unitary causes, in the sense that it is caused by two mutated copies of the CFTR gene on the $7^{\text {th }}$ chromosome and the non-existence of a counteracting mutation and the existence of carbon atoms). Two mutated copies of the CFTR gene on the $7^{\text {th }}$ chromosome is a deep cause in the sense that it operates in relative isolation to produce a narrow range of outcomes through an identified mechanism. 


\section{References}

Abdulkadir, M., Herle, M., De Stavola, B. L., Hübel, C., Santos Ferreira, D. L., Loos, R. J., ... \& Micali, N. (2020). Polygenic score for body mass index is associated with disordered eating in a general population cohort. Journal of Clinical Medicine, 9, 1187. doi: $10.3390 /$ jcm 9041187

Abramovitch, R., Corter, C. M, \& Lando, B. (1979). Sibling interaction in the home. Child Development, 50, 997-1003. doi: 10.2307/1129325

Agnew-Blais, J. C., Belsky, D. W., Caspi, A., Danese, A., Moffitt, T. E., Polanczyk, G. V., ... \& Arseneault, L. (2021). Polygenic risk and the course of attention-deficit/hyperactivity disorder from childhood to young adulthood: Findings from a nationally representative cohort. Journal of the American Academy of Child \& Adolescent Psychiatry. doi: 10.1016/j.jaac.2020.12.033

Albert, D., Belsky, D. W., Crowley, D. M., Latendresse, S. J., Aliev, F., Riley, B., ... \& Dodge, K. A. (2015). Can genetics predict response to complex behavioral interventions? Evidence from a genetic analysis of the Fast Track Randomized Control Trial. Journal of Policy Analysis and Management, 34, 497-518. doi: 10.1002/pam.21811

Alda, M. (2015). Lithium in the treatment of bipolar disorder: pharmacology and pharmacogenetics. Molecular Psychiatry, 20, 661-670. doi: 10.1038/mp.2015.4

Almond, D. (2006). Is the 1918 influenza pandemic over? Long-term effects of in utero influenza exposure in the post-1940 U.S. population. Journal of Political Economy, 114, 672-712. doi: $10.1086 / 507154$

Almond, D., Currie, J., \& Duque, V. (2018). Childhood circumstances and adult outcomes: Act II. Journal of Economic Literature, 56, 1360-1446. doi: 10.1257/jel.20171164 
1123 Angrist, J. D. (2004). Treatment effect heterogeneity in theory and practice. The Economic

$1124 \quad$ Journal, 114, C52-C83. doi: 10.1111/j.0013-0133.2003.00195.x

1125 Bailey, D. H., Duncan, G. J., Cunha, F., Foorman, B. R., \& Yeager, D. S. (2020). Persistence and

1126 fade-out of educational-intervention effects: Mechanisms and potential

1127 solutions. Psychological Science in the Public Interest, 21, 55-97. doi:

$1128 \quad 10.1177 / 1529100620915848$

1129 Bates, J. (2020, December 30). 2020 ends as one of America's most violent years in decades.

1130 Time Magazine. Retrived from https://time.com/5922082/2020-gun-violence-homicides-

1131 record-year/

1132 Batmanian, L., Ridge, J., \& Worrall, S. (2011). Biochemistry for health professionals. Elsevier $1133 \quad$ Australia.

1134 Belfield, C. R., Nores, M., Barnett, S., \& Schweinhart, L. (2006). The High/Scope Perry

1135 Preschool Program cost-benefit analysis using data from the age-40 followup. Journal of 1136 Human Resources, 41, 162-190. doi: 10.3368/jhr.XLI.1.162

1137 Belsky, D. W., Domingue, B. W., Wedow, R., Arseneault, L., Boardman, J. D., Caspi, A., ...

1138 Harris, K. M. (2018). Genetic analysis of social-class mobility in five longitudinal

1139 studies. Proceedings of the National Academy of Sciences, 115, E7275-E7284. doi:

$1140 \quad 10.1073 /$ pnas. 1801238115

1141 Belsky, D. W., \& Harden, K. P. (2019). Phenotypic annotation: Using polygenic scores to 1142 translate discoveries from genome-wide association studies from the top down. Current 1143 Directions in Psychological Science, 28, 82-90. doi: 10.1177/0963721418807729

1144 Belsky, D. W., Moffitt, T. E., Houts, R., Bennett, G. G., Biddle, A. K., Blumenthal, J. A., ... \& 1145 Caspi, A. (2012). Polygenic risk, rapid childhood growth, and the development of 
obesity: Evidence from a 4-decade longitudinal study. Archives of Pediatrics \& Adolescent Medicine, 166, 515-521. doi: 10.1001/archpediatrics.2012.131

1148 Belsky, D. W., Moffitt, T. E., Baker, T. B., Biddle, A. K., Evans, J. P., Harrington, H., ... \& 1149 Caspi, A. (2013). Polygenic risk and the developmental progression to heavy, persistent 1150 smoking and nicotine dependence: Evidence from a 4-decade longitudinal study. JAMA $1151 \quad$ Psychiatry, 70, 534-542. doi: 10.1001/jamapsychiatry.2013.736

1152 Belsky, D. W., Moffitt, T. E., \& Caspi, A. (2013). Genetics in population health science:

$1153 \quad$ Strategies and opportunities. American Journal of Public Health, 103, S73-S83. doi: 10.2105/AJPH.2012.301139

1155 Belsky, D. W., Moffitt, T. E., Corcoran, D. L., Domingue, B., Harrington, H., Hogan, S., ... \& Caspi, A. (2016). The genetics of success: How single-nucleotide polymorphisms associated with educational attainment relate to life-course development. Psychological Science, 27, 957-972. doi: 10.1177/0956797616643070

1159 Bierut, L. J. (2011). Genetic vulnerability and susceptibility to substance dependence. Neuron, 69, 618-627. doi: 10.1016/j.neuron.2011.02.015

1161 Block, N. (1995). How heritability misleads about race. Cognition, 56, 99-128. doi: 10.1016/0010-0277(95)00678-R

1163 Bonell, C., Fletcher, A., Morton, M., Lorenc, T., \& Moore, L. (2012). Realist randomised controlled trials: a new approach to evaluating complex public health interventions. Social Science \& Medicine, 75, 2299-2306. doi: 10.1016/j.socscimed.2012.08.032

1167 Borges, J. L. (2018). The garden of forking paths. Penguin. (Original work published in 1941). 
1168 Bork, P., Dandekar, T., Diaz-Lazcoz, Y., Eisenhaber, F., Huynen, M., \& Yuan, Y. (1998).

1169 Predicting function: From genes to genomes and back. Journal of Molecular Biology,

283, 707-725. doi: 10.1006/jmbi.1998.2144

1171 Bourrat, P. (2020). Causation and single nucleotide polymorphism heritability. Philosophy of

$1172 \quad$ Science, $87,1073-1083$. doi: 10.1086/710517

1173 Bowie, G. L. (1979). The similarity approach to counterfactuals: Some problems. Nô̂s, 477-498.

1174 doi: $10.2307 / 2215340$

1175 Boyle, E. A., Li, Y. I., \& Pritchard, J. K. (2017). An expanded view of complex traits: From

1176 polygenic to omnigenic. Cell, 169, 1177-1186. doi: 10.1016/j.cell.2017.05.038

1177 Brady, H. E. (2011). Causation and explanation in social science. Oxford University Press. doi:

$1178 \quad$ 10.1093/oxfordhb/9780199604456.013.0049

1179 Brody, G. H., Beach, S. R., Philibert, R. A., Chen, Y. F., Lei, M. K., Murry, V. M., \& Brown, A.

1180 C. (2009). Parenting moderates a genetic vulnerability factor in longitudinal increases in

1181 youths' substance use. Journal of Consulting and Clinical Psychology, 77, 1-11. doi:

$1182 \quad 10.1037 / \mathrm{a} 0012996$

1183 Brody, G. H., Beach, S. R., Hill, K. G., Howe, G. W., Prado, G., \& Fullerton, S. M. (2013).

1184 Using genetically informed, randomized prevention trials to test etiological hypotheses

1185 about child and adolescent drug use and psychopathology. American Journal of Public

1186 Health, 103, S19-S24. doi: 10.2105/AJPH.2012.301080

1187 Browning, S. R., \& Browning, B. L. (2011). Haplotype phasing: Existing methods and new

1188 developments. Nature Reviews Genetics, 12, 703-714. doi: 10.1038/nrg3054

1189 Brumpton, B., Sanderson, E., Heilbron, K., Hartwig, F. P., Harrison, S., Vie, G. Å., ... Davies,

1190 N. M. (2020). Avoiding dynastic, assortative mating, and population stratification biases 
in Mendelian randomization through within-family analyses. Nature Communications, 11, 3519. doi: 10.1038/s41467-020-17117-4

1193 Bryan, C. J., Tipton, E., \& Yeager, D. S. (2021). Behavioural science is unlikely to change the 1194 world without a heterogeneity revolution. Nature Human Behaviour, 1-10.

1195 Buniello, A., MacArthur, J. A. L., Cerezo, M., Harris, L. W., Hayhurst, J., Malangone, C., ...

1196 Parkinson, H. (2019). The NHGRI-EBI GWAS Catalog of published genome-wide association studies, targeted arrays and summary statistics 2019. Nucleic Acids Research,

1198 47, D1005-D1012. doi: 10.1093/nar/gky1120

1199 Cade, J. F. (1949). Lithium salts in the treatment of psychotic excitement. Medical Journal of $1200 \quad$ Australia.

1201 Cardon, L. R., \& Palmer, L. J. (2003). Population stratification and spurious allelic association. 1202 The Lancet, 361, 598-604. doi: 10.1016/S0140-6736(03)12520-2

1203 Carey, G. (1986). Sibling imitation and contrast effects. Behavior Genetics, 16, 319-341. doi: 1204 10.1007/BF01071314

1205 Carroll, D. (2001). Genetic recombination. In Encyclopedia of Genetics (pp. 841-845). Elsevier. 1206 doi: 10.1006/rwgn.2001.0543

1207 Carroll, S. B. (2020). A series of fortunate events: Chance and the making of the planet, life, and 1208 you. Princeton University Press.

1209 Cartwright, N. (1988). Regular associations and singular causes. In B. Skyrms \& W. L. Harper 1210 (Eds.), Causation, Chance and Credence (pp. 79-97). Springer Netherlands. doi: 10.1007/978-94-009-2863-3_5

1212 Cartwright, N. (1995). Precis of Nature's Capacities and Their Measurement. Philosophy and 1213 Phenomenological Research, 55, 153-156. doi: 10.2307/2108313 
1214 Chabris, C. F., Lee, J. J., Cesarini, D., Benjamin, D. J., \& Laibson, D. I. (2015). The fourth law

1215 of behavior genetics. Current Directions in Psychological Science, 24, 304-312. doi:

$1216 \quad 10.1177 / 0963721415580430$

1217 Charlton, W. (1983). Causation and change. Philosophy, 58, 143-160. doi:

$1218 \quad 10.1017 / \mathrm{S} 0031819100068650$

1219 Coleman, J. R. I., Peyrot, W. J., Purves, K. L., Davis, K. A. S., Rayner, C., Choi, S. W., ...

1220 Breen, G. (2020). Genome-wide gene-environment analyses of major depressive disorder

1221 and reported lifetime traumatic experiences in UK Biobank. Molecular Psychiatry, 25,

1222 1430-1446. doi: 10.1038/s41380-019-0546-6

1223 Collins, F. S., \& McKusick, V. A. (2001). Implications of the Human Genome Project for

1224 medical science. JAMA, 285, 540-544. doi: 10.1001/jama.285.5.540

1225 Connolly, S., \& Heron, E. A. (2015). Review of statistical methodologies for the detection of

1226 parent-of-origin effects in family trio genome-wide association data with binary disease

1227 traits. Briefings in Bioinformatics, 16, 429-448. doi: 10.1093/bib/bbu017

1228 Corvin, A., Craddock, N., \& Sullivan, P. F. (2010). Genome-wide association studies: A primer.

1229 Psychological Medicine, 40, 1063-1077. doi: 10.1017/S0033291709991723

1230 Cox, J. W., Rich, S., Chiu, A., Muyskens, J., \& Ulmanu, M. (2018). More than 228,000 students

1231 have experienced gun violence at school since Columbine. Washington Post. Retrieved

1232 from https://www.washingtonpost.com/graphics/2018/local/school-shootings-database/.

1233 Craver, C. F., \& Darden, L. (2013). In search of mechanisms: Discoveries across the life

1234 sciences. The University of Chicago Press.

1235 Cronbach, L. J. (1957). The two disciplines of scientific psychology. American Psychologist, 12,

1236 671. doi: $10.1037 / \mathrm{h} 0043943$ 
1237 Cutting, G. R. (2015). Cystic fibrosis genetics: From molecular understanding to clinical application. Nature Reviews Genetics, 16, 45-56. doi: 10.1038/nrg3849

1239 Davey Smith, G., \& Ebrahim, S. (2003). 'Mendelian randomization': Can genetic epidemiology contribute to understanding environmental determinants of disease? International Journal of Epidemiology, 32, 1-22. doi: 10.1093/ije/dyg070

1242 Davies, N. M., Howe, L. J., Brumpton, B., Havdahl, A., Evans, D. M., \& Davey Smith, G. (2019). Within family Mendelian randomization studies. Human Molecular Genetics, 28, R170-R179. doi: 10.1093/hmg/ddz204

1245 Dawkins, R. (2016). The extended phenotype: The long reach of the gene. Oxford University Press. (Original work published in 1982).

1247 Deaton, A., \& Cartwright, N. (2018). Understanding and misunderstanding randomized controlled trials. Social Science \& Medicine, 210, 2-21. doi: 10.1016/j.socscimed.2017.12.005

Dick, D. M. (2018). Commentary for special issue of prevention science "using genetics in prevention: Science fiction or science fact?”. Prevention Science, 19, 101-108. doi: $10.1007 / \mathrm{s} 11121-017-0828-7$

Dick, D. M., Barr, P. B., Cho, S. B., Cooke, M. E., Kuo, S. I. C., Lewis, T. J., ... \& Su, J. (2018). Post-GWAS in psychiatric genetics: A developmental perspective on the "other" next steps. Genes, Brain and Behavior, 17, e12447. doi: 10.1111/gbb.12447

Dolan, C. V., de Kort, J. M., van Beijsterveldt, T. C. E. M., Bartels, M., \& Boomsma, D. I. (2014). GE covariance through phenotype to environment transmission: An assessment in longitudinal twin data and application to childhood anxiety. Behavior Genetics, 44, 240253. doi: 10.1007/s10519-014-9659-5 
1260 Draaisma, D. (2019). Lithium: the gripping history of a psychiatric success story. Nature, 572, $1261 \quad 584-586$

1262 Duncan, L. E., Ostacher, M., \& Ballon, J. (2019). How genome-wide association studies

1263 (GWAS) made traditional candidate gene studies obsolete. Neuropsychopharmacology,

$1264 \quad 44,1518-1523$. doi: 10.1038/s41386-019-0389-5

1265 Eaves, L. (1976). A model for sibling effects in man. Heredity, 36, 205-214. doi:

1266 10.1038/hdy.1976.25

1267 Elborn, J. S. (2016). Cystic fibrosis. The Lancet, 388, 2519-2531. doi: 10.1016/S0140-

$1268 \quad 6736(16) 00576-6$

1269 Engel, G. (1977). The need for a new medical model: A challenge for biomedicine. Science, 196, 1270 129-136. doi: $10.1126 /$ science. 847460

1271 Engzell, P., \& Tropf, F. C. (2019). Heritability of education rises with intergenerational mobility. $1272 \quad$ Proceedings of the National Academy of Sciences, 116, 25386-25388. doi:

$1273 \quad 10.1073 /$ pnas.1912998116

1274 Evangelou, E., Warren, H. R., Mosen-Ansorena, D., Mifsud, B., Pazoki, R., Gao, H., ...

1275 Caulfield, M. J. (2018). Genetic analysis of over 1 million people identifies 535 new loci 1276 associated with blood pressure traits. Nature Genetics, 50, 1412-1425. doi:

$1277 \quad 10.1038 / \mathrm{s} 41588-018-0205-\mathrm{x}$

1278 Feldman, M. W, \& Lewontin, R. C (1975). The heritability hang-up. Science, 190, 1163-1168.

1279 doi: $10.1126 /$ science. 1198102

1280 Fisher, R. A. (1925). Statistical methods for research workers (11th ed. rev.). Edinburgh: Oliver $1281 \quad$ and Boyd.

1282 Fisher, R. A. (1935). The design of experiments. Edinburgh: Oliver and Boyd. 
1283 Fletcher, J. M., Wu, Y., Zhao, Z., \& Lu, Q. (2020). The production of within-family inequality:

1284 Insights and implications of integrating genetic data. bioRxiv. doi:

1285 $10.1101 / 2020.06 .06 .137778$

1286 Fletcher, J.M, Wu, Y., Li, T., \& Lu, Q. (2021). Interpreting polygenic score effects in sibling analysis. bioRxiv. doi: 10.1101/2021.07.16.452740

1288 Fox, D. (2019). Subversive science. Penn St. L. Rev., 124, 153.

1289 Funder, D. C., \& Ozer, D. J. (2019). Evaluating effect size in psychological research: Sense and 1290 nonsense. Advances in Methods and Practices in Psychological Science, 2, 156-168. doi: $10.1177 / 2515245919847202$

1292 Galton, F. (1869). Hereditary genius: An inquiry into its laws and consequences. Macmillan and $1293 \quad$ Co. doi: $10.1037 / 13474-000$

1294 Gaskell, G., Bard, I., Allansdottir, A., Da Cunha, R. V., Eduard, P., Hampel, J., ... \& Zwart, H. 1295 (2017). Public views on gene editing and its uses. Nature Biotechnology, 35, 1021-1023. 1296 doi: $10.1038 /$ nbt.3958

1297 Gelman, A., \& Loken, E. (2014). The statistical crisis in science. American Scientist, 102, 4601298 465. doi: $10.1511 / 2014.111 .460$

1299 Glennan, S. S. (1996). Mechanisms and the nature of causation. Erkenntnis, 44, 49-71. doi: $1300 \quad 10.1007 / \mathrm{BF} 00172853$

1301 Gough, A., Stern, A. M., Maier, J., Lezon, T., Shun, T.-Y., Chennubhotla, C., ... Taylor, D. L. 1302 (2017). Biologically relevant heterogeneity: Metrics and practical insights. SLAS 1303 Discovery, 22, 213-237. doi: 10.1177/2472555216682725 
1304 Green, C. S. (2020). Interventions to do real-world good: Generalization and

1305

1306

1307

1308

1309

1310

1311

1312

1313

1314

1315

1316

1317

1318

1319

1320

1321

1322

1323

1324

persistence. Psychological Science in the Public Interest, 21, 43-49. doi:

$10.1177 / 1529100620933847$

Grotzinger, A. D., Rhemtulla, M., de Vlaming, R., Ritchie, S. J., Mallard, T. T., Hill, W. D., ... Tucker-Drob, E. M. (2019). Genomic structural equation modelling provides insights into the multivariate genetic architecture of complex traits. Nature Human Behaviour, 3, 513525. doi: 10.1038/s41562-019-0566-X

Gueron, J. M., \& Rolston, H. (2013). Fighting for reliable evidence. Russell Sage Foundation.

Gurr, T. R. (1981). Historical trends in violent crime: A critical review of the evidence. Crime and Justice, 3, 295-353. doi: 10.1086/449082

Harrison, P. J., Cipriani, A., Harmer, C. J., Nobre, A. C., Saunders, K., Goodwin, G. M., \& Geddes, J. R. (2016). Innovative approaches to bipolar disorder and its treatment. Annals of the New York Academy of Sciences, 1366, 76. doi: 10.1111/nyas.13048

Hausman, D. M. (2005). Causal relata: Tokens, types, or variables? Erkenntnis, 63, 33-54. doi: $10.1007 / \mathrm{s} 10670-005-0562-6$

Haworth, S., Mitchell, R., Corbin, L., Wade, K. H., Dudding, T., Budu-Aggrey, A., ... Timpson, N. J. (2019). Apparent latent structure within the UK Biobank sample has implications for epidemiological analysis. Nature Communications, 10, 333. doi: 10.1038/s41467018-08219-1

Heckman, J. J. (2006). Skill formation and the economics of investing in disadvantaged children. Science, 312, 1900-1902. doi: 10.1126/science.1128898 
1325 Heckman, J. J., Moon, S. H., Pinto, R., Savelyev, P. A., \& Yavitz, A. (2010). The rate of return 1326 to the HighScope Perry Preschool Program. Journal of Public Economics, 94, 114-128. 1327 doi: $10.1016 /$ j.jpubeco.2009.11.001

1328 Herd, P., Freese, J., Sicinski, K., Domingue, B. W., Mullan Harris, K., Wei, C., \& Hauser, R. M. 1329 (2019). Genes, gender inequality, and educational attainment. American Sociological 1330 Review, 84, 1069-1098. doi: 10.1177/0003122419886550

1331 Herle, M., Abdulkadir, M., Hübel, C., Ferreira, D. S., Bryant-Waugh, R., Loos, R. J., ... \& 1332 Micali, N. (2021). The genomics of childhood eating behaviours. Nature Human 1333 Behaviour, 5, 625-630. doi: 10.1038/s41562-020-01019-y

1334 Herle, M., Pickles, A., \& de Stavola, B. (2021, June). Can interventions mitigate genomic 1335 liability for obesity? Using causal inference based mediation analyses in genetically-

1338 Herrnstein, R. J., \& Murray, C. A. (1996). The bell curve: Intelligence and class structure in 1339 American life (1st Free Press pbk. ed). Simon \& Schuster.

1340 Hill, A. B. (2015). The environment and disease: Association or causation? Journal of the Royal $1341 \quad$ Society of Medicine, 108, 32-37. (Original work published in 1965). doi: $10.1177 / 0141076814562718$

1343 Hill, W. D., Davies, N. M., Ritchie, S. J., Skene, N. G., Bryois, J., Bell, S., .. Deary, I. J. (2019). 1344 Genome-wide analysis identifies molecular systems and 149 genetic loci associated with 1345 income. Nature Communications, 10, 5741. doi: 10.1038/s41467-019-13585-5

1346 Holland, P. W. (1986). Statistics and causal inference. Journal of the American Statistical 1347 Association, 81, 945-960. doi: 10.1080/01621459.1986.10478354 
1348 Holland, P. W. (1988). Causal inference, path analysis, and recursive structural equations

1349 models. In Sociological Methodology, Ed. C. Clogg, pp. 449-484. Washington D.C.:

$1350 \quad$ American Sociological Association. doi: 10.2307/271055

1351 Howe, L. J., Nivard, M. G., Morris, T. T., Hansen, A. F., Rasheed, H., Cho, Y., ... \& Within

1352 Family Consortium. (2021). Within-sibship GWAS improve estimates of direct genetic

$1353 \quad$ effects. bioRxiv. doi: 10.1101/2021.03.05.433935

1354 Hudgens, M. G., \& Halloran, M. E. (2008). Toward causal inference with interference. Journal

1355 of the American Statistical Association, 103, 832-842. doi:

$1356 \quad 10.1198 / 016214508000000292$

1357 Hulswit, M. (2002). From cause to causation: A Peircean perspective. Springer Netherlands.

1358 Hume, D. (1999). An enquiry concerning human understanding (T. L. Beauchamp, Ed.). Oxford

1359 University Press. (Original work published in 1748).

1360 Jaffee, S. R., \& Price, T. S. (2007). Gene-environment correlations: A review of the evidence

1361 and implications for prevention of mental illness. Molecular Psychiatry, 12, 432-442.

1362 doi: $10.1038 /$ sj.mp.4001950

1363 Janzen, T. (2021). Autosomal DNA testing comparison chart. In International Society of Genetic

1364 Genealogy Wiki. Retrieved from

1365 https://isogg.org/wiki/Autosomal_DNA_testing_comparison_chart

1366 Jensen, A. (1969). How much can we boost IQ and scholastic achievement? Harvard

1367 Educational Review, 39, 1-123. doi: 10.17763/haer.39.1.13u15956627424k7

1368 Jo, B., \& Muthén, B. (2001). Modeling of intervention effects with noncompliance: A latent

1369 variable modeling approach for randomized trials. In G. A. Marcoulides \& R. E. 

(pp. 57-87). Lawrence Erlbaum Associates.

1372 Juvenal. (1769). The satires of Juvenal translated: With explanatory and classical notes, relating to the laws and customs of the Greeks and Romans. Dublin. Printed by George Faulkner.

1374 Kapogiannis, D., Barbey, A. K., Su, M., Zamboni, G., Krueger, F., \& Grafman, J. (2009).

1375 Cognitive and neural foundations of religious belief. Proceedings of the National Academy of Sciences, 106, 4876-4881. doi: 10.1073/pnas.0811717106

1377 Karlsson Linnér, R., Biroli, P., Kong, E., Meddens, S. F. W., Wedow, R., Fontana, M. A., ... Beauchamp, J. P. (2019). Genome-wide association analyses of risk tolerance and risky behaviors in over 1 million individuals identify hundreds of loci and shared genetic influences. Nature Genetics, 51, 245-257. doi: 10.1038/s41588-018-0309-3

Keller, E. F. (2010). The mirage of a space between nature and nurture. Duke University Press.

Kendler, K. S. (2005). "A gene for...”: The nature of gene action in psychiatric disorders. American Journal of Psychiatry, 162, 1243-1252. doi: 10.1176/appi.ajp.162.7.1243 ... \& Dick, D. M. (2021). Multivariate analysis of 1.5 million people identifies genetic associations with traits related to self-regulation and addiction. Nature Neuroscience, 24, 1367-1376. doi: 10.1038/s41593-021-00908-3

Kendler, K. S., Chen, X., Dick, D., Maes, H., Gillespie, N., Neale, M. C., \& Riley, B. (2012). Recent advances in the genetic epidemiology and molecular genetics of substance use disorders. Nature Neuroscience, 15, 181-189. doi: 10.1038/nn.3018 
1391 Kent, D. M., Rothwell, P. M., Ioannidis, J. P. A., Altman, D. G., \& Hayward, R. A. (2010).

1392 Assessing and reporting heterogeneity in treatment effects in clinical trials: A proposal.

1393 Trials, 11, 85. doi: 10.1186/1745-6215-11-85

1394 Kevles, D. J. (1995). In the name of eugenics: Genetics and the uses of human heredity (1st

1395 Harvard University Press pbk. ed). Harvard University Press.

1396 Khatri, P., Sirota, M., \& Butte, A. J. (2012). Ten years of pathway analysis: current approaches

1397 and outstanding challenges. PLoS Computational Biology, 8, e1002375. doi:

$1398 \quad$ 10.1371/journal.pcbi.1002375

1399 Kong, A., Thorleifsson, G., Frigge, M. L., Vilhjalmsson, B. J., Young, A. I., Thorgeirsson, T. E.,

1400 ... Stefansson, K. (2018). The nature of nurture: Effects of parental genotypes. Science,

$1401 \quad 359,424-428$. doi: 10.1126/science.aan6877

1402 Kuo, S.I, Salvatore, J. E., Aliev, F., Ha, T., Dishion, T. J., \& Dick, D. M. (2019). The family

1403 check-up intervention moderates polygenic influences on long-term alcohol outcomes:

1404 Results from a randomized intervention trial. Prevention Science, 20, 975-985. doi:

$1405 \quad 10.1007 / \mathrm{s} 11121-019-01024-2$

1406 Lahey, B. B., Waldman, I. D., \& McBurnett, K. (1999). Annotation: The development of

1407 antisocial behavior: An integrative causal model. The Journal of Child Psychology and

1408 Psychiatry and Allied Disciplines, 40, 669-682.

1409 Lakoff, G. (1993). The contemporary theory of metaphor. In A. Ortony (Ed.), Metaphor and

1410 Thought (2nd ed., pp. 202-251). Cambridge University Press. doi:

$1411 \quad 10.1017 / C B O 9781139173865.013$ 
1412 Lawlor, D. A., Tilling, K., \& Davey Smith, G. (2017). Triangulation in aetiological

1413 epidemiology. International Journal of Epidemiology, 45, 1866-1886. doi:

$1414 \quad 10.1093 / \mathrm{ije} / \mathrm{dyw} 314$

1415 Lee, J. J., Wedow, R., Okbay, A., Kong, E., Maghzian, O., Zacher, M., ... Cesarini, D. (2018).

1416 Gene discovery and polygenic prediction from a genome-wide association study of

1417 educational attainment in 1.1 million individuals. Nature Genetics, 50, 1112-1121. doi:

$1418 \quad 10.1038 / \mathrm{s} 41588-018-0147-3$

1419 LeGrys, V. A. (1996). Sweat testing for the diagnosis of cystic fibrosis: Practical considerations.

1420 The Journal of Pediatrics, 129, 892-897. doi: 10.1016/S0022-3476(96)70034-3

1421 Lewis, D. (1973a). Counterfactuals (Rev. ed.). Blackwell Publishers.

1422 Lewis, D. (1973b). Causation. The Journal of Philosophy, 70, 556-567. doi: 10.2307/2025310

1423 Lewontin, R. C. (2006). The analysis of variance and the analysis of causes. International

$1424 \quad$ Journal of Epidemiology, 35, 520-525. (Original work published in 1974). doi:

$1425 \quad 10.1093 / \mathrm{ije} / \mathrm{dy} 1062$

1426 Li, S., Zhao, J. H., Luan, J. A., Ekelund, U., Luben, R. N., Khaw, K. T., ... \& Loos, R. J. (2010).

1427 Physical activity attenuates the genetic predisposition to obesity in 20,000 men and

1428 women from EPIC-Norfolk prospective population study. PLoS Medicine, 7, e1000332.

1429 doi: 10.1371/journal.pmed.1000332

1430 Locke, J. (1997). An essay concerning human understanding (R. S. Woolhouse, Ed.). New

$1431 \quad$ York : Penguin Books. (Original work published in 1690).

1432 Loehlin, J. C. (2009). History of behavior genetics. In Kim YK (Ed.), Handbook of Behavior

1433 Genetics (pp. 3-11). Springer New York. doi: 10.1007/978-0-387-76727-7_1 
1434 Lowe, J. (2015). I don't believe in God, but I believe in Lithium'. The New York Times, 25.

1435 Retrieved from https://www.nytimes.com/2015/06/28/magazine/i-dont-believe-in-god-

1436 but-i-believe-in-lithium.html

1437 Mackie, J. L. (1965). Causes and conditions. American Philosophical Quarterly, 2, 245-264.

1438 Martin, A. R., Gignoux, C. R., Walters, R. K., Wojcik, G. L., Neale, B. M., Gravel, S., ...

1439 Kenny, E. E. (2017). Human demographic history impacts genetic risk prediction across

1440 diverse populations. The American Journal of Human Genetics, 100, 635-649. doi:

$1441 \quad$ 10.1016/j.ajhg.2017.03.004

1442 Martin, N. (2018). Getting to the genetic and environmental roots of educational inequality. Npj

1443 Science of Learning, 3, 4. doi: 10.1038/s41539-018-0021-1

1444 Meehl, P. E. (1972). Specific genetic etiology, psychodynamics, and therapeutic nihilism.

1445 International Journal of Mental Health, 1, 10-27. doi:

$1446 \quad 10.1080 / 00207411.1972 .11448562$

1447 Mertens, J., Wang, Q. W., Kim, Y., Diana, X. Y., Pham, S., Yang, B., ... \& Yao, J. (2015).

1448 Differential responses to lithium in hyperexcitable neurons from patients with bipolar

1449 disorder. Nature, 527, 95-99. doi: 10.1038/nature15526

1450 Meyer, M. N., Turley, P., \& Benjamin, D. J. (2020, February 3). Response to Charles Murray on

$1451 \quad$ polygenic scores. Medium. Retrieved from

1452 https://medium.com/@ michellenmeyer/response-to-charles-murray-on-polygenic-scores-

$1453 \quad$ e768cf145cc

1454 Mill, J. S. (2002). A system of logic. University Press of the Pacific. (Original work published in $1455 \quad 1843)$. 
1456 Miller, G. A. (2010). Mistreating psychology in the decades of the brain. Perspectives on Psychological Science, 5, 716-743. doi: 10.1177/1745691610388774

1458 Mills, M. C., \& Rahal, C. (2019). A scientometric review of genome-wide association studies. 1459 Communications Biology, 2, 9. doi: 10.1038/s42003-018-0261-x

1460 Moffitt, T. E. (2006). Life-course-persistent versus adolescence-limited antisocial behavior. In D.

1461 Cicchetti \& D. J. Cohen (Eds.), Developmental psychopathology: Risk, disorder, and 1462 adaptation (pp. 570-598). John Wiley \& Sons, Inc. doi: 10.1002/9780470939406.ch15

1463 Molenaar, P. C. M. (2004). A manifesto on psychology as idiographic science: Bringing the 1464 person back into scientific psychology, this time forever. Measurement: Interdisciplinary 1465 Research \& Perspective, 2, 201-218. doi: 10.1207/s15366359mea0204_1

1466 Moscati, A., Verhulst, B., McKee, K., Silberg, J., \& Eaves, L. (2018). Cross-lagged analysis of 1467 interplay between differential traits in sibling pairs: Validation and application to parenting behavior and ADHD symptomatology. Behavior Genetics, 48, 22-33. doi: $10.1007 / \mathrm{s} 10519-017-9882-\mathrm{y}$

Mostafavi, H., Harpak, A., Agarwal, I., Conley, D., Pritchard, J. K., \& Przeworski, M. (2020).

1473 Munafò, M. R. (2006). Candidate gene studies in the 21st century: Meta-analysis, mediation, moderation. Genes, Brain and Behavior, 5, 3-8. doi: 10.1111/j.1601-183X.2006.00188.x

1475 Munafò, M. R., \& Flint, J. (2009). Replication and heterogeneity in genexenvironment 1476 interaction studies. The International Journal of Neuropsychopharmacology, 12, 727729. doi: $10.1017 / \mathrm{S} 1461145709000479$ 
1478 Murray, C. A. (2020). Human diversity: The biology of gender, race, and class (First edition).

$1479 \quad$ New York: Twelve.

1480 Nachman, M. W. (2002). Variation in recombination rate across the genome: Evidence and

1481 implications. Current Opinion in Genetics \& Development, 12, 657-663. doi:

1482 $10.1016 / \mathrm{S} 0959-437 \mathrm{X}(02) 00358-1$

1483 Nagy, A., Perrimon, N., Sandmeyer, S., \& Plasterk, R. (2003). Tailoring the genome: The power 1484 of genetic approaches. Nature Genetics, 33, 276-284. doi: 10.1038/ng1115

1485 Nielsen, J. B., Thorolfsdottir, R. B., Fritsche, L. G., Zhou, W., Skov, M. W., Graham, S. E., ... 1486 Willer, C. J. (2018). Biobank-driven genomic discovery yields new insight into atrial 1487 fibrillation biology. Nature Genetics, 50, 1234-1239. doi: 10.1038/s41588-018-0171-3

1488 Obama, B. (2013). State of the Union address 2013 [Transcript]. Retrieved from 1489 https://obamawhitehouse.archives.gov/the-press-office/2013/02/12/remarks-president$1490 \quad$ state-union-address

1491 Okbay, A., Beauchamp, J. P., Fontana, M. A., Lee, J. J., Pers, T. H., Rietveld, C. A., ...

1492 Benjamin, D. J. (2016). Genome-wide association study identifies 74 loci associated with 1493 educational attainment. Nature, 533, 539-542. doi: 10.1038/nature17671

1494 Pearl, J. (2009). Causal inference in statistics: An overview. Statistics Surveys, 3, 96-146. doi: $1495 \quad 10.1214 / 09-S S 057$

1496 Pearl J. (2010). The mathematics of causal relations. In Causality and Psychopathology, ed. PE 1497 Shrout, pp. 47-65. New York: Oxford Univ. Press

1498 Pearl, J. (2018). Theoretical impediments to machine learning with seven sparks from the causal 1499 revolution. arXiv. Retreived from https://arxiv.org/abs/1801.04016 
1500 Perkel, J. (2008). SNP genotyping: Six technologies that keyed a revolution. Nature Methods, 5, 1501 447-453. doi: 10.1038/nmeth0508-447

1502 Phillips, M. S., Lawrence, R., Sachidanandam, R., Morris, A. P., Balding, D. J., Donaldson, M. 1503 A., ... Cardon, L. R. (2003). Chromosome-wide distribution of haplotype blocks and the role of recombination hot spots. Nature Genetics, 33, 382-387. doi: 10.1038/ng1100

1505 Plomin, R., DeFries, J. C., Knopik, V. S., \& Neiderhiser, J. M. (2013). Behavioral genetics: A 1506 primer (Sixth edition). Worth Publishers.

1507 Plomin, R., DeFries, J. C., \& Loehlin, J. C. (1977). Genotype-environment interaction and 1508 correlation in the analysis of human behavior. Psychological Bulletin, 84, 309-322. doi: 10.1037/0033-2909.84.2.309

1510 Plomin, R., \& von Stumm, S. (2018). The new genetics of intelligence. Nature Reviews Genetics, 1511 19, 148-159. doi: 10.1038/nrg.2017.104

1512 Price, A. L., Patterson, N. J., Plenge, R. M., Weinblatt, M. E., Shadick, N. A., \& Reich, D. 1513 (2006). Principal components analysis corrects for stratification in genome-wide association studies. Nature Genetics, 38, 904-909. doi: 10.1038/ng1847

Qi, Q., Chu, A. Y., Kang, J. H., Jensen, M. K., Curhan, G. C., Pasquale, L. R., ... \& Qi, L. 1518 Rietveld, C. A., Medland, S. E., Derringer, J., Yang, J., Esko, T., Martin, N. W., ... Koellinger, 1519 P. D. (2013). GWAS of 126,559 individuals identifies genetic variants associated with 1520 educational attainment. Science, 340, 1467-1471. doi: 10.1126/science.1235488 
1521 Rimfeld, K., Krapohl, E., Trzaskowski, M., Coleman, J. R. I., Selzam, S., Dale, P. S., ... \&

1522 Plomin, R. (2018). Genetic influence on social outcomes during and after the Soviet era 1523 in Estonia. Nature Human Behaviour, 2, 269-275. doi: 10.1038/s41562-018-0332-5

1524 Rosenbaum, P. R. (2007). Interference between units in randomized experiments. Journal of the 1525 American Statistical Association, 102, 191-200. doi: 10.1198/016214506000001112

1526 Ross, L. N. (2015). Causal control: A rationale for causal selection. PhilSci Archive. Retrieved 1527 from http://philsci-archive.pitt.edu/id/eprint/11743

1528 Ross, L. N. (2018). The doctrine of specific etiology. Biology \& Philosophy, 33, 37. doi: 10.1007/s10539-018-9647-X

Ross, L. N. (2019). Explanation in contexts of causal complexity: Lessons from psychiatric genetics. PhilSci Archive. Retrieved from http://philsci-archive.pitt.edu/id/eprint/15728

1532 Rottman, B. M., \& Hastie, R. (2014). Reasoning about causal relationships: Inferences on causal networks. Psychological Bulletin, 140, 109-139. doi: 10.1037/a0031903

1534 Rubin, D. B. (1974). Estimating causal effects of treatments in randomized and nonrandomized studies. Journal of Educational Psychology, 66, 688-701. doi: 10.1037/h0037350

1536 Rubin, D. B. (1980). Comment on: "Randomization analysis of experimental data in the fisher randomization test” by D. Basu. Journal of the American Statistical Association, 75, 591593. doi: $10.2307 / 2287653$

Rubin, D. B. (1986). Comment: Which ifs have causal answers. Journal of the American Statistical Association, 81, 961-962. doi: 10.1080/01621459.1986.10478355

1541 Rubin, D. B. (2005). Causal inference using potential outcomes: Design, modeling, decisions. 1542 Journal of the American Statistical Association, 100, 322-331. doi:

$1543 \quad 10.1198 / 016214504000001880$ 
1544 Salganik, M. J., Lundberg, I., Kindel, A. T., Ahearn, C. E., Al-Ghoneim, K., Almaatouq, A., ... 1545 McLanahan, S. (2020). Measuring the predictability of life outcomes with a scientific 1546 mass collaboration. Proceedings of the National Academy of Sciences, 117, 8398-8403. 1547 doi: $10.1073 /$ pnas. 1915006117

1548 Samek, D. R., McGue, M., Keyes, M., \& Iacono, W. G. (2015). Sibling facilitation mediates the 1549 association between older and younger sibling alcohol use in late adolescence. Journal of 1550 Research on Adolescence, 25, 638-651. doi: 10.1111/jora.12154

1551 Samorodnitsky, D. (2020, January 24). A study tried to use genetics to explain why people are 1552 poor. Vice. Retrieved from https://www.vice.com/en/article/jgepv8/a-study-tried-to-use1553 genetics-to-explain-why-people-are-poor

1554 Santos, R., Linker, S. B., Stern, S., Mendes, A. P., Shokhirev, M. N., Erikson, G., ... \& Gage, F. 1555 1556 1557 1558 Scarr, S., \& McCartney, K. (1983). How people make their own environments: A theory of 1559 genotype environment effects. Child Development, 54, 424-435. doi: 10.1111/j.14678624.1983.tb03884.x

1561 Schaefer, G. B., \& Thompson, J. N. (2014). Medical genetics: An integrated approach. 1562 McGraw-Hill Education.

1563 Schneider, B., \& Bradford, L. (2020). What we are learning about fade-out of intervention 1564 effects: A commentary. Psychological Science in the Public Interest, 21, 50-54. doi: 1565 $10.1177 / 1529100620935793$ 
1566 Schweinhart, L. J., Barnes, H. V., \& Weikart, D. P. (1993). Significant benefits: The High/Scope 1567 Perry preschool study through age 27. Monographs of the High/Scope Educational 1568 Research Foundation, No. 10. Ypsilanti, MI: High/Scope Press.

1569 Scott, J. (1988). Social network analysis. Sociology, 22, 109-127. doi: $10.1177 / 0038038588022001007$

1571 Selzam, S., Ritchie, S. J., Pingault, J.-B., Reynolds, C. A., O’Reilly, P. F., \& Plomin, R. (2019).

1572 Comparing within- and between-family polygenic score prediction. The American Journal of Human Genetics, 105, 351-363. doi: 10.1016/j.ajhg.2019.06.006

1574 Sobel, M. E. (2006). What do randomized studies of housing mobility demonstrate? Causal 1575 1576 inference in the face of interference. Journal of the American Statistical Association, 101, 1398-1407. doi: 10.1198/016214506000000636

1577 Spencer, C. C. A., Deloukas, P., Hunt, S., Mullikin, J., Myers, S., Silverman, B., ... McVean, G. 1578 1579 (2006). The influence of recombination on human genetic diversity. PLoS Genetics, 2, e148. doi: 10.1371/journal.pgen.0020148

1580 Stern, S., Santos, R., Marchetto, M. C., Mendes, A. P. D., Rouleau, G. A., Biesmans, S., ... \& 1581 Gage, F. H. (2018). Neurons derived from patients with bipolar disorder divide into intrinsically different sub-populations of neurons, predicting the patients' responsiveness

1584 Sugrue, L. P., \& Desikan, R. S. (2019). What are polygenic scores and why are they important? 1585 JAMA, 321, 1820-1821. doi: 10.1001/jama.2019.3893

1586 Thomas, J. G., \& Sharp, P. B. (2019). Mechanistic science: A new approach to comprehensive 1587 psychopathology research that relates psychological and biological phenomena. Clinical 1588 Psychological Science, 7, 196-215. doi: 10.1177/2167702618810223 
1589 Tielbeek, J. J., Johansson, A., Polderman, T. J. C., Rautiainen, M.-R., Jansen, P., Taylor, M., ...

1590 Posthuma, D. (2017). Genome-wide association studies of a broad spectrum of antisocial behavior. JAMA Psychiatry, 74, 1242-1250. doi: 10.1001/jamapsychiatry.2017.3069

1592 Tropf, F. C., Lee, S. H., Verweij, R. M., Stulp, G., van der Most, P. J., de Vlaming, R., ... Mills, M. C. (2017). Hidden heritability due to heterogeneity across seven populations. Nature Human Behaviour, 1, 757-765. doi: 10.1038/s41562-017-0195-1

Turkheimer, E. (1998). Heritability and biological explanation. Psychological Review, 105, 782791. doi: 10.1037/0033-295X.105.4.782-791

1597 Turkheimer, E. (2011). Commentary: Variation and causation in the environment and genome. International Journal of Epidemiology, 40, 598-601. doi: 10.1093/ije/dyq147

1599 Turkheimer, E., \& Gottesman, I. I. (1996). Simulating the dynamics of genes and environment in 1600 development. Development and Psychopathology, 8, 667-677. doi: $10.1017 /$ S0954579400007355

1602 Uchiyama, R., Spicer, R., \& Muthukrishna, M. (2021). Cultural evolution of genetic 1603 heritability. Behavioral and Brain Sciences, 1-147. doi: 10.1017/S0140525X21000893

1604 Venter, J. C., Adams, M. D., Myers, E. W., Li, P. W., Mural, R. J., Sutton, G. G., .. Zhu, X. 1605 1606 (2001). The sequence of the human genome. Science, 291, 1304-1351. doi: 10.1126/science. 1058040

Volkmann, C., Bschor, T., \& Köhler, S. (2020). Lithium treatment over the lifespan in bipolar disorders. Frontiers in Psychiatry, 11, 377. doi: 10.3389/fpsyt.2020.00377

1609 Wang, N., Akey, J. M., Zhang, K., Chakraborty, R., \& Jin, L. (2002). Distribution of 1610 recombination crossovers and the origin of haplotype blocks: The interplay of population 
history, recombination, and mutation. The American Journal of Human Genetics, 71, 1227-1234. doi: 10.1086/344398

1613 Warner, J. (2018, July 26). Why we shouldn't embrace the genetics of education. Inside Higher

$1614 E d$. Retrieved from https://www.insidehighered.com/blogs/just-visiting/why-we-

1615 shouldnt-embrace-genetics-education

1616 Watanabe, K., Mirkov, M. U., de Leeuw, C. A., van den Heuvel, M. P., \& Posthuma, D. (2019).

1617 Genetic mapping of cell type specificity for complex traits. Nature Communications, 10,

1618 1-13. doi: 10.1038/s41467-019-11181-1

1619 Watanabe, K., Taskesen, E., van Bochoven, A., \& Posthuma, D. (2017). Functional mapping and annotation of genetic associations with FUMA. Nature Communications, 8, 1826. doi:

1622 Waters, C. K. (2007). Causes that make a difference. The Journal of Philosophy, 104, 551-579. 1623 doi: 10.5840/jphil2007104111

1624 White, M. J., Yaspan, B. L., Veatch, O. J., Goddard, P., Risse-Adams, O. S., \& Contreras, M. G. 1625 (2019). Strategies for pathway analysis using GWAS and WGS data. Current Protocols 1626 in Human Genetics, 100, e79. doi: 10.1002/cphg.79

1627 Woodward, J. (2002). What is a mechanism? A counterfactual account. Philosophy of Science, $1628 \quad$ 69, S366-S377. doi: 10.1086/341859

1629 Woodward, J. (2005). Making things happen: A theory of causal explanation (Oxford Univ. 1630 Press paperback). Oxford Univ. Press.

1631 Woodward, J. (2010). Causation in biology: Stability, specificity, and the choice of levels of 1632 explanation. Biology \& Philosophy, 25, 287-318. doi: 10.1007/s10539-010-9200-z 
1633 Yang, J., Zaitlen, N. A., Goddard, M. E., Visscher, P. M., \& Price, A. L. (2014). Advantages and 1634 pitfalls in the application of mixed-model association methods. Nature Genetics, 46, 1001635 106. doi: $10.1038 / n g .2876$

1636 Yang, J., Zeng, J., Goddard, M. E., Wray, N. R., \& Visscher, P. M. (2017). Concepts, estimation 1637 and interpretation of SNP-based heritability. Nature Genetics, 49, 1304-1310. doi:

$1638 \quad 10.1038 /$ ng.3941

1639 Young, A. I., Benonisdottir, S., Przeworski, M., \& Kong, A. (2019). Deconstructing the sources 1640 of genotype-phenotype associations in humans. Science, 365, 1396-1400. doi:

$1641 \quad 10.1126 /$ science.aax3710

1642 Young, A. I., Frigge, M. L., Gudbjartsson, D. F., Thorleifsson, G., Bjornsdottir, G., Sulem, P., ... 1643 \& Kong, A. (2018). Relatedness disequilibrium regression estimates heritability without 1644 environmental bias. Nature Genetics, 50, 1304-1310. doi: 10.1038/s41588-018-0178-9

1645 Zaidi, A. A., \& Mathieson, I. (2020). Demographic history mediates the effect of stratification on 1646 polygenic scores. Elife, 9, e61548. doi: 10.7554/eLife.61548 